\title{
Mechanisms of Lithogenic Bile Formation in American Indian Women with Cholesterol Gallstones
}

\author{
Scott M. Grundy, Allan L. Metzger, and Ronald D. Adler \\ From the Phoenix Clinical Research Section, National Institute of Arthritis, \\ Metabolism, and Digestive Diseases, Phoenix Indian Medical Center, \\ Phoenix, Arizona 85016
}

A в S T R A C T Hepatic secretions of biliary lipids were estimated in 43 patients with and without cholesterol gallstones. Studies were carried out by a marker dilution technique employing duodenal intubation with a threelumen tube. Hourly secretion rates of cholesterol, bile acids. and phospholipids were determined during constant infusion with liquid formula.

In 17 American Indian women with gallstones, hourly outputs of biliary bile acids were significantly less than those in 7 Indian men and 12 Caucasian women without gallstones. These findings suggest that a decreased hepatic secretion of bile acids contributes significantly to the production of a lithogenic bile in Indian women. However, in Indian women with gallstones, secretion of biliary cholesterol was also significantly increased, as compared with Caucasian women without stones. Therefore, lithogenic bile in Indian women was, in most cases. due to a combined decrease in bile acid output and increase in cholesterol secretion.

In an attempt to determine the mechanisms for these abnormalities, cholesterol balance studies were done in Indian women with gallstones and normal Indian men. Balance data were compared with results reported previously in non-Indian patients studied by the same techniques, and in general, Indian women showed a slight increase in fecal excretion of bile acids. Since bile acids in the enterohepatic circulation were relatively depleted in Indian women, these patients had a reduced fractional reabsorption. However. previous studies have shown that Caucasians can rapidly replenish bile acid pools in the presence of much greater intestinal losses, and it is suggested that among Indian women with gallstones, reduced secretion rates of bile acids are primarily the

This work was presented in part at a meeting of the American Society for Clinical Investigation and published in abstract form: 1972. J. Clin. Inv'est. 51: 39a.

Receized for publication 28 April 1972 and in revised form 8 August 1972. result of defective homeostatic regulation of bile acid synthesis.

In Indian women with gallstones, at least two factors may have contributed to an increased availability of cholesterol in the liver for secretion into bile. First, cholesterol was inadequately converted into bile acids, and secondly, an increased amount of cholesterol was synthesized, as shown by the balance technique. This enhanced production of cholesterol can partially be explained by obesity, but other factors may also play a role.

\section{INTRODUCTION}

Cholesterol gallstones in human beings are usually associated with lithogenic bile, i.e., bile that contains more cholesterol than can be solubilized by the bile acid or phospholipid content (1). Recent studies indicate that lithogenic bile originates in the liver rather than in the gallbladder (2): hence, abnormal bile could result from an increased hepatic secretion of cholesterol, from a decreased output of bile acids and/or phospholipids in bile, or from a combination of these changes.

Vlahcevic and associates $(3,4)$ have recently shown that patients with lithogenic bile and cholesterol gallstones generally have reduced pool sizes of bile acids. Thus, they have postulated that lithogenic bile is primarily due to a deficiency of bile acids relative to cholesterol. However, previous studies have not provided direct measurements of hepatic secretion rates of biliary lipids, and they have not adequately determined whether secretion of cholesterol is normal or increased. Therefore, it was the purpose of the present study to examine factors responsible for production of lithogenic bile by measuring secretion rates directly.

Measurement of outputs of biliary lipids were carried out by an intubation technique recently developed by us (5). This method estimates hourly rates of hepatic secretion of cholesterol, bile acids, and phospholipids in pa- 
TABLE I

Clinicat Data: Indian Women with Gallstones

\begin{tabular}{|c|c|c|c|c|c|c|c|c|}
\hline \multirow[t]{2}{*}{ Patient } & \multirow{2}{*}{$\frac{\text { Age }}{y r}$} & \multirow[t]{2}{*}{ Tribe } & \multirow{2}{*}{$\frac{\text { Height }}{\mathrm{cm}}$} & \multicolumn{2}{|c|}{$\begin{array}{l}\text { Weight and } \\
\text { per cent of } \\
\text { ideal wt }\end{array}$} & \multirow{2}{*}{$\begin{array}{c}\begin{array}{c}\text { Plasma } \\
\text { cholesterol }\end{array} \\
m g / 100 m l\end{array}$} & \multirow{2}{*}{$\begin{array}{c}\begin{array}{c}\text { Plasma } \\
\text { triglyceride }\end{array} \\
m g / 100 m l\end{array}$} & \multirow[t]{2}{*}{$\begin{array}{c}\text { Oral } \\
\text { cholecystogram* }\end{array}$} \\
\hline & & & & $\mathrm{kg}$ & $\%$ & & & \\
\hline M. G. & 16 & Papago & 160 & 65 & 122 & 137 & 88 & V \\
\hline P. B. & 19 & Navajo & 155 & 55 & 117 & 117 & 107 & NV \\
\hline L. N. & 19 & Papago-Pima & 162 & 84 & 155 & 160 & 一 & NV \\
\hline C. P. & 21 & Pima & 155 & 52 & 106 & 199 & 269 & NV \\
\hline S. N. & 22 & Pima & 149 & 76 & 160 & 153 & 95 & NV \\
\hline L. W. & 23 & Pima & 152 & 54 & 125 & 109 & 86 & V \\
\hline C. J. & 23 & Pima & 159 & 79 & 149 & 188 & 184 & V \\
\hline Le. W. & 24 & Apache & 152 & 70 & 142 & 148 & 174 & NV \\
\hline M. E. & 27 & Hopi & 154 & 47 & 100 & 172 & 106 & NV \\
\hline A. P. & 27 & Papago & 147 & 54 & 108 & 132 & 70 & NV \\
\hline V. A. & 28 & Pima & 154 & 61 & 122 & 148 & 249 & $\mathrm{~V}$ \\
\hline C. P. & 28 & Papago & 142 & 100 & 194 & 121 & 94 & NV \\
\hline D. G. & 29 & Pima & 152 & 52 & 162 & 122 & 110 & V \\
\hline S. H. & 29 & Mohave & 154 & 84 & 164 & 174 & 145 & V \\
\hline S. S. & 31 & Pima & 157 & 64 & 123 & 164 & 221 & V \\
\hline M. L. & 31 & Pima & 162 & 92 & 167 & 181 & 78 & V \\
\hline R. H. & 32 & Apache-Pima & 162 & 51 & 94 & 109 & 82 & 一 \\
\hline J. Y. & 35 & Maricopa & 152 & 67 & 136 & 152 & 183 & V \\
\hline W. J. & 40 & Pima & 157 & 68 & 130 & 210 & 152 & V \\
\hline A. A. & 41 & Papago & 156 & 65 & 130 & 163 & 210 & V \\
\hline L. E. & 51 & Papago-Mexican & 162 & 82 & 141 & 196 & 279 & V \\
\hline M. B. & 53 & Navajo & 158 & 61 & 109 & 210 & - & V \\
\hline
\end{tabular}

${ }^{*} \mathrm{~V}$, visualizing gallbladder; $\mathrm{NV}$, nonvisualizing gallbladder.

tients with an intact enterohepatic circulation. We have applied this technique to the study of American Indian women who are particularly prone to development of cholesterol gallstones (6), and the results were compared with those obtained from three groups of subjects without stones-Indian men, Indian women, and Caucasian women. The findings showed that Indian women with stones have two abnormalities leading to the production of lithogenic bile; not only were bile acids secreted at a reduced rate by the liver, as might have been predicted from the studies of Vlahcevic and associates $(3,4)$, but also, outputs of cholesterol were increased. Therefore, production of lithogenic bile in Indian women with gallstones was due to a combined defect in sterol metabolism.

These studies were extended by applying the sterol balance technique. The balance results suggested that the decreased secretion of bile acids was primarily due to a defective feedback regulation of bile acid synthesis and that increased cholesterol output was mainly the result of increased cholesterol synthesis.

\section{METHODS}

Patients. Studies were carried out on the metabolic wards of the Phoenix Indian Medical Center, Phoenix,
Ariz., and at the Clinical Center, National Institutes of Health (NIH), Bethesda, Md.

22 Indian women with gallstones were selected from patients admitted for elective cholecystectomy (Table I). These patients represented a variety of tribes of the Southwest, predominately Pima and Papago. Their ages ranged from 16 to $53 \mathrm{yr}$ (mean $29 \mathrm{yr}$ ). They were generally overweight [average per cent ideal weight (7), 134\%]; their serum cholesterol levels were typically low (mean $158 \mathrm{mg} /$ $100 \mathrm{ml}$ ). 13 patients had visualizing gallbladders with cholelithiasis on oral cholecystography; in all eight patients who had nonvisualization of gallbladders, gallstones were demonstrated at time of surgery. The patency of the biliary tract was confirmed by operative cholangiograms. In one patient (R. H.), cholecystography was not done because gallstones had been palpated at laparotomy several years before; stones were found to be present at subsequent cholecystectomy. No patient had acute cholecystitis, evidence of biliary obstruction, or abnormal liver function tests at time of study. Seven patients had non-insulin-dependent diabetes mellitus, a frequency typical of southwestern Indians.

Findings for these patients were compared with those from three groups of subjects without gallstones: $(a)$ six Indian women, $(b)$ nine Indian men, and $(c) 13$ Caucasian women. Clinical data on these three groups are shown in Tables II and III.

The ages of the 6 Indian women without gallstones ranged from 28 to $58 \mathrm{yr}$. The mean age $(41 \mathrm{yr})$ of this group was higher than that of patients with gallstones, but the average per cent of ideal weight $(123 \%)$ was lower. The absence 
TABLE II

Clinical Data: Indian Women and Men without Gallstones

\begin{tabular}{|c|c|c|c|c|c|c|c|}
\hline \multirow[t]{2}{*}{ Patient } & \multirow{3}{*}{$\frac{\text { Age }}{y r}$} & \multirow[t]{2}{*}{ Tribe } & \multirow{2}{*}{$\frac{\text { Height }}{\mathrm{cm}}$} & \multicolumn{2}{|c|}{$\begin{array}{l}\text { Weight and } \\
\text { per cent of } \\
\text { ideal wt }\end{array}$} & \multirow{3}{*}{$\begin{array}{c}\begin{array}{c}\text { Plasma } \\
\text { cholesterol }\end{array} \\
m g / 100 m l\end{array}$} & \multirow{3}{*}{$\frac{\begin{array}{c}\text { Plasma } \\
\text { triglyceride }\end{array}}{m g / 100 \mathrm{ml}}$} \\
\hline & & & & $\mathrm{kg}$ & $\%$ & & \\
\hline Women & & & & & & & \\
\hline M. W. & 28 & Hopi & 155 & 79 & 158 & 153 & 91 \\
\hline C. I. & 34 & Cherokee & 165 & 50 & 96 & 137 & 40 \\
\hline I. T. & 38 & Chippewa & 142 & 74 & 102 & 131 & 192 \\
\hline A. W. & 38 & Hualapai & 165 & 43 & 130 & 210 & 133 \\
\hline C. V. & 47 & Papago & 160 & 76 & 146 & 227 & 188 \\
\hline O. K. & 58 & Navajo & 143 & 52 & 104 & 188 & 92 \\
\hline \multicolumn{8}{|l|}{ Men } \\
\hline A. Mo. & 22 & Pima & 167 & 85 & 110 & 159 & 91 \\
\hline A. M. & 27 & Pima & 169 & 72 & 118 & 180 & 121 \\
\hline E. S. D. & 28 & Cocopah & 178 & 129 & 161 & 118 & 79 \\
\hline L. P. & 30 & Papago & 170 & 74 & 115 & 150 & 59 \\
\hline R. W. & 33 & Navajo & 157 & 68 & 115 & 143 & 66 \\
\hline F.S. & 34 & Papago & 173 & 84 & 120 & 160 & 104 \\
\hline E. S. & 39 & Sioux & 182 & 80 & 111 & 150 & 239 \\
\hline L. S. & 43 & $\begin{array}{l}\text { Papago- } \\
\text { Yaqui }\end{array}$ & 173 & 130 & 178 & 162 & 124 \\
\hline A. G. & 47 & Papago & 175 & 88 & 129 & 150 & 212 \\
\hline J. D. & 63 & $\begin{array}{l}\text { Maricopa- } \\
\text { Klammath }\end{array}$ & 167 & 93 & 140 & 164 & 78 \\
\hline
\end{tabular}

of gallstones was proven by cholecystography. None of them had diabetes mellitus or liver disease.

The nine Indian men ranged in age from 22 to $47 \mathrm{yr}$ (mean $34 \mathrm{yr}$ ). These Indian men were typically less obese than Indian women with gallstones. Several of them had a history of excessive intake of alcohol, but none had abnormal liver function tests during the study. Plasma cholesterol concentrations averaged $152 \mathrm{mg} / 100 \mathrm{ml}$. Although absence of gallstones was not proven by cholecystography, all patients were asymptomatic, and the prevalence of stones is low in this age group (6).

12 Caucasian women without gallstones were recruited through the NIH normal volunteer program. Seven subjects were studied at the NIH Clinical Center in Bethesda, and five others were studied in Phoenix. As shown in Table III, ages ranged from 19 to $21 \mathrm{yr}$; mean per cent ideal body weight for the group was $100 \%$, and plasma cholesterol averaged $167 \mathrm{mg} / 100 \mathrm{ml}$. A $25 \mathrm{yr}$ old Caucasian subject (L. A.) included in the study was not from the normal volunteer program; she was markedly overweight (per cent ideal weight, $184 \%$ ). All patients were asymptomatic, and no cholecystograms were done.

Experimental design. In this study, lipid metabolism was investigated by two different approaches. First, hourly rates of hepatic secretions of biliary lipids were estimated using a duodenal intubation technique. Second, cholesterol and bile acid synthesis and excretion were studied with the cholesterol balance method. The details of these techniques have been presented elsewhere, but their essential features are briefly described below. These methods were applied to the groups previously described, as follows:

Indian women with gallstones were studied for periods ranging from 3 to 21 days. 20 patients were fed a mixed diet of solid food and formula containing $40 \%$ of calories as fat. The composition of this diet (Table IV) was similar to that found to be typical of Pima Indian women by Reid and associates (8). These workers observed that Indian women with gallstones did not exclude fatty foods before surgery. Therefore, it was assumed that the study diet was comparable to diets taken before admission. Hepatic secretion of biliary lipids were determined on 17 patients at the end of their dietary period. In seven women, measurements of cholesterol balance were also carried out for at least 2 wk on the $40 \%$ fat diet. Two additional patients were studied on a diet containing $5 \%$ of calories as fat for $2 \mathrm{wk}$.

Indian women and men without gallstones were started on the same diet containing $40 \%$ fat upon hospitalization. After varying periods in the hospital, measurements of biliary lipid secretions were made on six women and six men. In addition, cholesterol balance studies were carried out for $2-4$ wk on six men.

Caucasian women without gallstones included two subgroups. The seven subjects who were studied at the NIH Clinical Center in Bethesda received ad lib hospital diets before their intubation studies; on review of menus available to these subjects, we estimated that their diets had contained approximately $40 \%$ of calories as fat. The six additional normal volunteers studied in Phoenix were given the diet containing $40 \%$ fat (Table IV) for $5 \mathrm{wk}$ before the intubation study.

Both Indian and Caucasian subjects tolerated the mixed solid food-formula diet well. Since the lactose content of this diet was minimal, there was no diarrhea due to lactose intolerance, which is a common disorder among Indians. In fact, this diet caused neither constipation, which can occur with pure formula diets, nor abnormally loose stools. No differences were noted between bowel habits of Indians and Caucasians. 
Hourly outputs of biliary lipids were measured, as described by Grundy and Metzger (5). This method required intubation of subjects with a three-lumen tube. By roentgenographic guidance, the tube was positioned in the duodenum with two proximal outlets located in the second portion of the duodenum, adjacent to the ampulla of Vater and the third outlet $10 \mathrm{~cm}$ distally, just beyond the ligament of Treitz. After proper placement, the tube was fixed tightly at the mouth, and subsequent roentgenograms were taken if there was any indication that the tube had moved out of position. However, follow-up roentgenographic studies on many patients have shown that slippage of the tube rarely occurs.

Liquid formulas containing fat, carbohydrate, and protein (9) were infused through one proximal outlet at a rate calculated to provide the subject's daily caloric requirement. Formulas contained $40 \%$ of calories as fat in the form of lard. Thus, the distribution of calories in the formula was almost identical to that of the subject's diet (Table IV). $\beta$-sitosterol, mixed with formula, was infused at a constant rate as an internal marker, while duodenal contents were simultaneously and constantly aspirated from the other two outlets. Less than $5 \%$ of intestinal contents passing both sites was aspirated.

Hourly outputs of biliary cholesterol were determined by marker dilution principles from the sample withdrawn distally. Using $\beta$-sitosterol as a marker, the output of cholesterol was calculated according to the following equation:

$$
\begin{gathered}
\text { Cholesterol output }(\mathrm{mg} / \mathrm{hr})=\beta \text {-sitosterol input } \\
(\mathrm{mg} / \mathrm{hr}) \times[\text { cholesterol withdrawn }(\mathrm{mg} / \mathrm{hr}) \\
\div \beta \text {-sitosterol withdrawn }(\mathrm{mg} / \mathrm{hr})] \text {. }
\end{gathered}
$$

Calculation of bile acid and phospholipid outputs was as follows :

Bile acid (or phospholipid) output $(\mathrm{mg} / \mathrm{hr})=$ cholesterol output $(\mathrm{mg} / \mathrm{hr}) \times[$ bile acid (or phospholipid) to cholesterol ratio],

where cholesterol output was that determined from the sample obtained distally (Equation 1), and ratios of bile acids (or phospholipids) to cholesterol were those found on samples from the proximal aspiration site.

Values for biliary lipid output obtained during the first 4-6 $\mathrm{hr}$ of study were not included in the results since we have previously shown that during this period, hepatic bile is contaminated with gallbladder bile (5). After this initial period of gallbladder contraction, values for hourly outputs became reasonably constant, especially for cholesterol and phospholipids. The outputs of bile acids were more variable due to irregularities in the intestinal phase of their enterohepatic circulation. Studies in many patients have demonstrated that constancy in cholesterol and phospholipid output is maintained for up to $30 \mathrm{hr}$ of formula infusion. It seems unlikely that this constancy could have been achieved if the gallbladder had continued to empty significant amounts of residual bile after the first $6 \mathrm{hr}$ or if there was appreciable intermittent filling and emptying of the gallbladder. Therefore, we have assumed that after the initial gallbladder contraction the gallbladder was functionally inactive during the subsequent hours of constant infusion of liquid formula; if this were indeed the case, duodenal outputs of lipids should correspond to their rates of hepatic secretion. Biliary outputs of cholesterol, bile acids, and phospholipids were determined hourly for 6-16 hr during this steady-state infusion period. Multiple hourly determinations were made on each patient in an attempt to obtain a more representative

\begin{tabular}{|c|c|c|c|c|c|c|}
\hline \multirow[t]{2}{*}{ Patient } & \multirow{2}{*}{$\frac{\text { Age }}{y r}$} & \multirow{2}{*}{$\begin{array}{c}\text { Height } \\
\mathrm{cm}\end{array}$} & \multicolumn{2}{|c|}{$\begin{array}{l}\text { Weight and } \\
\text { per cent of } \\
\text { ideal wt }\end{array}$} & \multirow{2}{*}{$\begin{array}{c}\begin{array}{c}\text { Plasma } \\
\text { cholesterol }\end{array} \\
m g / 100 m l\end{array}$} & \multirow{2}{*}{$\frac{\begin{array}{c}\text { Plasma } \\
\text { triglycerides }\end{array}}{m g / 100 m l}$} \\
\hline & & & $k g$ & $\%$ & & \\
\hline J. K. & 19 & 167 & 52 & 100 & 154 & - \\
\hline A. D. & 21 & 169 & 50 & 83 & 202 & - \\
\hline E. R. & 19 & 161 & 51 & 96 & 156 & - \\
\hline M. J. & 21 & 150 & 50 & 106 & 170 & - \\
\hline S. S. & 19 & 157 & 52 & 98 & 161 & 72 \\
\hline A. F. & 20 & 167 & 54 & 93 & 178 & 73 \\
\hline R. B. & 21 & 166 & 54 & 98 & 168 & 一 \\
\hline D. N. & 19 & 160 & 64 & 116 & 146 & 72 \\
\hline S. T. & 19 & 157 & 57 & 107 & 152 & 84 \\
\hline B. $\mathrm{O}$. & 19 & 157 & 52 & 100 & 135 & 60 \\
\hline M. Bo. & 19 & 159 & 56 & 105 & 197 & 78 \\
\hline S. C. & 19 & 160 & 58 & 107 & 187 & 73 \\
\hline L. A. & 25 & 159 & 97 & 183 & 214 & 167 \\
\hline
\end{tabular}

TABLE III

Clinical Data: Caucasian Women without Gallstones*

* First seven subjects were studied in Bethesda, Md., and the remaining in Phoenix, Ariz.

average for hepatic secretion rates. This procedure reduces the likelihood for significant errors due to transitory inconstancies in gallbladder function, mixing of markers, etc.

Statistical analyses of the results were carried out using an approximate $t$ test (10). This procedure was used in preference to the usual Student's $t$ test since the variances between these different groups were shown to be unequal in most cases.

Biliary lipid composition. Samples obtained from the proximal site adjacent to the ampulla of Vater were analyzed for cholesterol, bile acid, and phospholipid content.

\begin{tabular}{|c|c|c|c|c|c|}
\hline Time & Item & $\begin{array}{l}\text { Per cent } \\
\text { protein }\end{array}$ & $\begin{array}{c}\text { Per cent } \\
\text { fat }\end{array}$ & $\begin{array}{c}\text { Per cent } \\
\text { carbohydrate }\end{array}$ & $\begin{array}{l}\text { Per cent } \\
\text { total }\end{array}$ \\
\hline $7: 30$ a.m. & Formula* & 2.2 & 8.0 & 6.3 & 16.5 \\
\hline \multirow{6}{*}{$11: 00$ a.m. } & Dry cereal & 0.3 & 一 & 3.9 & 4.2 \\
\hline & Bread & 0.3 & 0.2 & 2.0 & 2.5 \\
\hline & Skim milk & 2.0 & 0.1 & 1.7 & 3.8 \\
\hline & Lard & - & 4.1 & - & 4.1 \\
\hline & Sugar and jelly & - & 一 & 2.9 & 2.9 \\
\hline & Meal total & 2.6 & 4.4 & 10.5 & 17.5 \\
\hline 2:00 p.m. & Formula* & 2.2 & 8.0 & 6.3 & 16.5 \\
\hline \multirow{7}{*}{ 4:00 p.m. } & Beef patty & 4.7 & 1.5 & - & 6.2 \\
\hline & Potato & 0.4 & 0.1 & 4.3 & 4.8 \\
\hline & Bread & 0.3 & 0.2 & 2.0 & 2.5 \\
\hline & Lard & - & 8.1 & - & 8.1 \\
\hline & Cookies & 0.2 & 2.7 & 2.6 & 5.5 \\
\hline & Cola & 一 & - & 6.2 & 6.2 \\
\hline & Meal total & 5.6 & 12.6 & 15.1 & 33.3 \\
\hline \multirow[t]{2}{*}{$8: 00$ p.m. } & Formula* & 2.2 & .80 & 6.3 & 16.5 \\
\hline & Days total & 14.8 & 41.0 & 44.5 & $100.3 \ddagger$ \\
\hline
\end{tabular}

TABLE IV

Mixed Solid Food and Formula Diet

* Formula was composed of $40 \%$ fat as lard, $45 \%$ carbohydrate as dextrose and $15 \%$ protein as milk protein (RI-5, Ross Laboratories, Columbus, Ohio).

$\ddagger$ Cholesterol content of total diet $=150 \mathrm{mg} / 2000 \mathrm{cal}$. 
TABLE V

Outputs of Biliary Lipids in Indian Women with Gallstones

\begin{tabular}{|c|c|c|c|c|c|c|c|c|}
\hline \multirow[t]{2}{*}{ Subject } & \multirow[t]{2}{*}{$\begin{array}{l}\text { Hr: No.* of } \\
\text { determinations }\end{array}$} & \multicolumn{2}{|c|}{ Cholesterol } & \multicolumn{2}{|c|}{ Bile acids } & \multicolumn{2}{|c|}{ Phospholipids } & \multirow[t]{2}{*}{$\begin{array}{l}\text { Litho- } \\
\text { genic } \\
\text { index }\end{array}$} \\
\hline & & $\begin{array}{l}m g / h r \\
\pm \mathrm{SD}\end{array}$ & $\begin{array}{c}\text { molar } \\
\%\end{array}$ & $\begin{array}{c}m g / h r \\
\pm \mathrm{SD}\end{array}$ & $\begin{array}{c}\text { molar } \\
\%\end{array}$ & $\begin{array}{l}m g / h r \\
\pm \mathrm{SD}\end{array}$ & $\begin{array}{c}\text { molar } \\
\%\end{array}$ & \\
\hline M. G. & $8: 8$ & $33 \pm 5$ & 9 & $324 \pm 43$ & 65 & $201 \pm 63$ & 26 & 0.9 \\
\hline P. B. & $9: 9$ & $36 \pm 7$ & 8 & $402 \pm 203$ & 72 & $168 \pm 35$ & 20 & 0.8 \\
\hline C. P. & $10: 10$ & $37 \pm 6$ & 8 & $460 \pm 93$ & 72 & $198 \pm 65$ & 20 & 0.8 \\
\hline L. W. & $9: 9$ & $25 \pm 8$ & 10 & $239 \pm 56$ & 74 & $83 \pm 32$ & 16 & 1.0 \\
\hline Le. W. & $16: 8$ & $49 \pm 5$ & 9 & $470 \pm 229$ & 66 & $282 \pm 73$ & 25 & 0.9 \\
\hline M. E. & $8: 8$ & $41 \pm 5$ & 9 & $384 \pm 79$ & 68 & $200 \pm 43$ & 23 & 0.9 \\
\hline V. A. & $12: 6$ & $56 \pm 10$ & 14 & $324 \pm 163$ & 63 & $184 \pm 59$ & 23 & 1.3 \\
\hline D. G. & $10: 10$ & $39 \pm 6$ & 10 & $372 \pm 108$ & 74 & $127 \pm 31$ & 16 & 1.0 \\
\hline S. H. & $8: 8$ & $62 \pm 8$ & 10 & $600 \pm 181$ & 71 & $249 \pm 89$ & 19 & 1.0 \\
\hline S. S. & $7: 7$ & $40 \pm 5$ & 6 & $654 \pm 314$ & 72 & $325 \pm 90$ & 22 & 0.6 \\
\hline M. L. & $8: 8$ & $42 \pm 6$ & 10 & $356 \pm 160$ & 65 & $209 \pm 50$ & 25 & 1.0 \\
\hline R. H. & $9: 9$ & $34 \pm 7$ & 10 & $311 \pm 69$ & 70 & $133 \pm 30$ & 20 & 1.0 \\
\hline J. Y. & $10: 10$ & $52 \pm 7$ & 10 & $460 \pm 48$ & 67 & $242 \pm 56$ & 23 & 1.0 \\
\hline W. J. & $8: 8$ & $82 \pm 11$ & 11 & $719 \pm 177$ & 75 & $217 \pm 32$ & 14 & 1.1 \\
\hline A. A. & $9: 9$ & $49 \pm 5$ & 16 & $207 \pm 47$ & 51 & $212 \pm 83$ & 33 & 2.0 \\
\hline L. E. & $8: 8$ & $53 \pm 7$ & 7 & $625 \pm 129$ & 62 & $385 \pm 91$ & 31 & 0.7 \\
\hline C. J. & $8: 8$ & $72 \pm 9$ & 10 & $585 \pm 134$ & 64 & $369 \pm 66$ & 26 & 1.0 \\
\hline \multicolumn{2}{|c|}{ Average (mean \pm SEM) } & $47 \pm 4$ & & $440 \pm 36$ & & $228 \pm 23$ & & \\
\hline
\end{tabular}

* Duration of steady state (hr) and number of successive bile samples analyzed. Samples were withdrawn continuously, and the ratio of the two figures represents the number of hours per collection.

Therefore, bile lipid composition, as well as hourly secretion rates, could be continuously determined throughout each study. Bile composition was plotted on triangular coordinates according to the method of Admirand and Small (1) and was also expressed numerically as the "lithogenic index" (LI) (11). The latter expression indicates the degree to which a bile sample is saturated with cholesterol. For example, an index of 1.0 signifies that a point of lipid composition falls upon the line of maximum cholesterol solubility that was determined experimentally (1). When a bile sample is less than fully saturated with cholesterol, the in$\operatorname{dex}$ is less than 1.0, while it is greater than unity for a supersaturated (lithogenic) bile.

Sterol balance studies were carried out as described previously (12-14). All patients were maintained for 2-4 wk on a mixed solid food-formula diet (Table IV) with strict control of caloric intake to maintain constant body weight and to promote a metabolic steady state. Stools collected throughout the last 4-9 days of each dietary period were pooled for analysis of neutral and acidic steroids $(12,13)$. Intakes of cholesterol ranged from 100 to $300 \mathrm{mg} /$ day. $\beta$-sitosterol was used as an internal standard to correct for losses of neutral steroids (14); it was prepared from tall oil by Mann Research Laboratories, Inc., New York, and was further purified and converted into microcrystalline form by Mr. Erold Diller, Eli Lilly \& Co., Indianapolis, Ind. Each patient received $200 \mathrm{mg} \beta$-sitosterol twice daily in capsule form. Excretions of acidic steroids were corrected for variations in fecal flow by use of chromic oxide, as described by Davignon, Simmonds, and Ahrens (15).

Fecal neutral and acidic steroids were isolated separately, and their masses were determined by gas-liquid chromatography (GLC). GLC analysis of neutral steroids dis- tinguished between plant sterols and cholesterol, and between the two families of bacterial conversion derived from plant sterols and cholesterol during intestinal transit $(5 \alpha \mathrm{H}$, $3 \beta-\mathrm{OH}$, and $5 \alpha \mathrm{H}, 3$-keto compounds). Analyses were carried out entirely by chemical procedures; no radioactive isotopes were used in these patients.

\section{RESULTS}

\section{Outputs of biliary lipids}

Average hourly outputs of biliary lipids are given for all groups in Tables V, VI, and VII together with the molar per cent of each lipid component and the lithogenic index for each patient. These results are summarized in Table VIII, and they have also been normalized to 70 $\mathrm{kg}$ body weight, $70 \mathrm{~kg}$ ideal body weight, and square meters of body surface. Ideal weights were based on body height (7), while surface areas were calculated from height and weight (16). We suggest that normalization of results to ideal weight or surface area should provide a better comparison between groups than uncorrected results or those corrected to actual body weight. The advantage of this normalization is apparent only when there is considerable variation in body size or weight. For example, in obese patients, if biliary lipid outputs are based on the actual rather than ideal weight or surface area, results appear to be distorted towards inordinately low values. Nevertheless, in Table VIII, all of 
TABLE VI

Outputs of Biliary Lipids in Indian Men and Women without Gallstones

\begin{tabular}{|c|c|c|c|c|c|c|c|c|}
\hline \multirow[t]{2}{*}{ Subject } & \multirow[t]{2}{*}{$\begin{array}{c}\mathrm{Hr}: \text { No.* of } \\
\text { determinations }\end{array}$} & \multicolumn{2}{|c|}{ Cholesterol } & \multicolumn{2}{|c|}{ Bile acids } & \multicolumn{2}{|c|}{ Phospholipids } & \multirow[t]{2}{*}{$\begin{array}{l}\text { Litho- } \\
\text { genic } \\
\text { index }\end{array}$} \\
\hline & & $\begin{array}{l}m g / h r \\
\pm S D\end{array}$ & $\begin{array}{c}\text { molar } \\
\%\end{array}$ & $\begin{array}{c}m g / h r \\
\pm S D\end{array}$ & $\begin{array}{c}\text { molar } \\
\%\end{array}$ & $\begin{array}{c}m g / h r \\
\pm \mathrm{SD}\end{array}$ & $\begin{array}{c}\text { molar } \\
\%\end{array}$ & \\
\hline \multicolumn{9}{|l|}{ Women } \\
\hline C. L. & 9:9 & $19 \pm 2$ & 4 & $441 \pm 258$ & 79 & $140 \pm 55$ & 17 & 0.4 \\
\hline I. T. & $12: 6$ & $25 \pm 5$ & 6 & $369 \pm 171$ & 62 & $266 \pm 111$ & 32 & 0.6 \\
\hline A. $\mathrm{W}$. & $9: 9$ & $73 \pm 20$ & 10 & $655 \pm 352$ & 69 & $311 \pm 130$ & 21 & 1.0 \\
\hline O. K. & $7: 7$ & $30 \pm 10$ & 4 & $850 \pm 464$ & 83 & $205 \pm 148$ & 13 & 0.4 \\
\hline M. W. & $7: 7$ & $53 \pm 5$ & 9 & $452 \pm 213$ & 62 & $333 \pm 32$ & 29 & 0.9 \\
\hline C. V. & $8: 8$ & $39 \pm 3$ & 7 & $539 \pm 171$ & 70 & $284 \pm 38$ & 23 & 0.7 \\
\hline \multicolumn{2}{|c|}{ Average (mean \pm SEM) } & \multicolumn{2}{|l|}{$40 \pm 8$} & \multicolumn{2}{|l|}{$551 \pm 71$} & \multicolumn{2}{|l|}{$256 \pm 29$} & \\
\hline \multicolumn{9}{|l|}{ Men } \\
\hline R. W. & $16: 8$ & $47 \pm 10$ & 5 & $962 \pm 271$ & 77 & $345 \pm 80$ & 18 & 0.5 \\
\hline E. S. & $12: 6$ & $39 \pm 4$ & 5 & $777 \pm 160$ & 74 & $346 \pm 64$ & 21 & 0.5 \\
\hline L. S. & $6: 6$ & $49 \pm 13$ & 4 & $1324 \pm 623$ & 84 & $297 \pm 167$ & 12 & 0.4 \\
\hline A. $G$. & $16: 8$ & $85 \pm 10$ & 6 & $1385 \pm 614$ & 76 & $502 \pm 99$ & 18 & 0.6 \\
\hline A. $\mathrm{M}$. & $16: 8$ & $43 \pm 5$ & 4 & $1035 \pm 205$ & 83 & $258 \pm 67$ & 13 & 0.4 \\
\hline L. P. & $8: 8$ & $51 \pm 15$ & 6 & $954 \pm 403$ & 81 & $249 \pm 85$ & 13 & 0.7 \\
\hline A. Mo. & $8: 8$ & $25 \pm 5$ & 4 & $654 \pm 41$ & 80 & $202 \pm 41$ & 16 & 0.4 \\
\hline \multicolumn{2}{|c|}{ Average (mean \pm SEM) } & \multicolumn{2}{|l|}{$49 \pm 6$} & \multicolumn{2}{|l|}{$1013 \pm 101$} & \multicolumn{2}{|l|}{$314 \pm 37$} & \\
\hline
\end{tabular}

* See footnote to Table V.

the results are presented for purposes of comparison, and the statistical significances of the differences between each group and Indian women with gallstones are shown.

Cholesterol outputs. Average outputs of biliary cholesterol in 17 Indian women with gallstones ranged from
25 to $82 \mathrm{mg} / \mathrm{hr}$ (mean $47 \mathrm{mg} / \mathrm{hr}$ ). There was no correlation between outputs and ages of patients. Four of 17 patients in this group had nonvisualizing gallbladders, but their results were not different from others in the group.

TABLE VII

Outputs of Biliary Lipids in Caucasian Women without Gallstones

\begin{tabular}{|c|c|c|c|c|c|c|c|c|}
\hline \multirow[t]{2}{*}{ Subject } & \multirow[t]{2}{*}{$\begin{array}{c}\text { Hr: No.* of } \\
\text { determinations }\end{array}$} & \multicolumn{2}{|c|}{ Cholesterol } & \multicolumn{2}{|c|}{ Bile acids } & \multicolumn{2}{|c|}{ Phospholipids } & \multirow[t]{2}{*}{$\begin{array}{l}\text { Litho- } \\
\text { genic } \\
\text { index }\end{array}$} \\
\hline & & $\begin{array}{c}m g / h r \\
\pm \mathrm{SD}\end{array}$ & $\begin{array}{c}\text { molar } \\
\%\end{array}$ & $\begin{array}{l}m g / h r \\
\pm \mathrm{SD}\end{array}$ & $\begin{array}{c}\text { molar } \\
\%\end{array}$ & $\begin{array}{l}m g / h r \\
\pm S D\end{array}$ & $\begin{array}{c}\text { molar } \\
\%\end{array}$ & \\
\hline J. K. & $10: 10$ & $38 \pm 5$ & 5 & $746 \pm 217$ & 74 & $316 \pm 106$ & 21 & 0.5 \\
\hline A. D. & $8: 8$ & $20 \pm 1$ & 5 & $305 \pm 117$ & 60 & $311 \pm 304$ & 35 & 0.6 \\
\hline E. R. & $10: 10$ & $34 \pm 8$ & 3 & $1438 \pm 302$ & 86 & $281 \pm 47$ & 11 & 0.3 \\
\hline M. J. & $9: 9$ & $33 \pm 11$ & 2 & $1361 \pm 728$ & 76 & $611 \pm 196$ & 22 & 0.2 \\
\hline S. S. & $9: 9$ & $37 \pm 2$ & 2 & $1917 \pm 942$ & 86 & $428 \pm 52$ & 12 & 0.2 \\
\hline A. $F$. & $9: 9$ & $18 \pm 3$ & 3 & $772 \pm 219$ & 85 & $166 \pm 50$ & 12 & 0.3 \\
\hline R. B. & $7: 7$ & $23 \pm 2$ & 2 & $1385 \pm 530$ & 90 & $180 \pm 42$ & 8 & 0.3 \\
\hline D. N. & $7: 7$ & $29 \pm 5$ & 4 & $651 \pm 121$ & 80 . & $192 \pm 34$ & 16 & 0.4 \\
\hline S. T. & $8: 8$ & $29 \pm 7$ & 5 & $643 \pm 350$ & 80 & $196 \pm 52$ & 15 & 0.5 \\
\hline B. 0 . & $9: 9$ & $43 \pm 7$ & 7 & $581 \pm 124$ & 78 & $171 \pm 76$ & 15 & 0.7 \\
\hline M. B. & $8: 8$ & $19 \pm 4$ & 4 & $558 \pm 273$ & 83 & $136 \pm 36$ & 13 & 0.4 \\
\hline S. C. & $6: 6$ & $13 \pm 2$ & 4 & $325 \pm 107$ & 75 & $140 \pm 65$ & 21 & 0.5 \\
\hline \multicolumn{2}{|c|}{ Average (mean \pm SEM) } & $29 \pm 3$ & & $868 \pm 145$ & & $251 \pm 39$ & & \\
\hline L. A. & $9: 9$ & $39 \pm 5$ & 7 & $596 \pm 144$ & 81 & $132 \pm 22$ & 13 & 0.7 \\
\hline
\end{tabular}

* See footnote to Table V. 


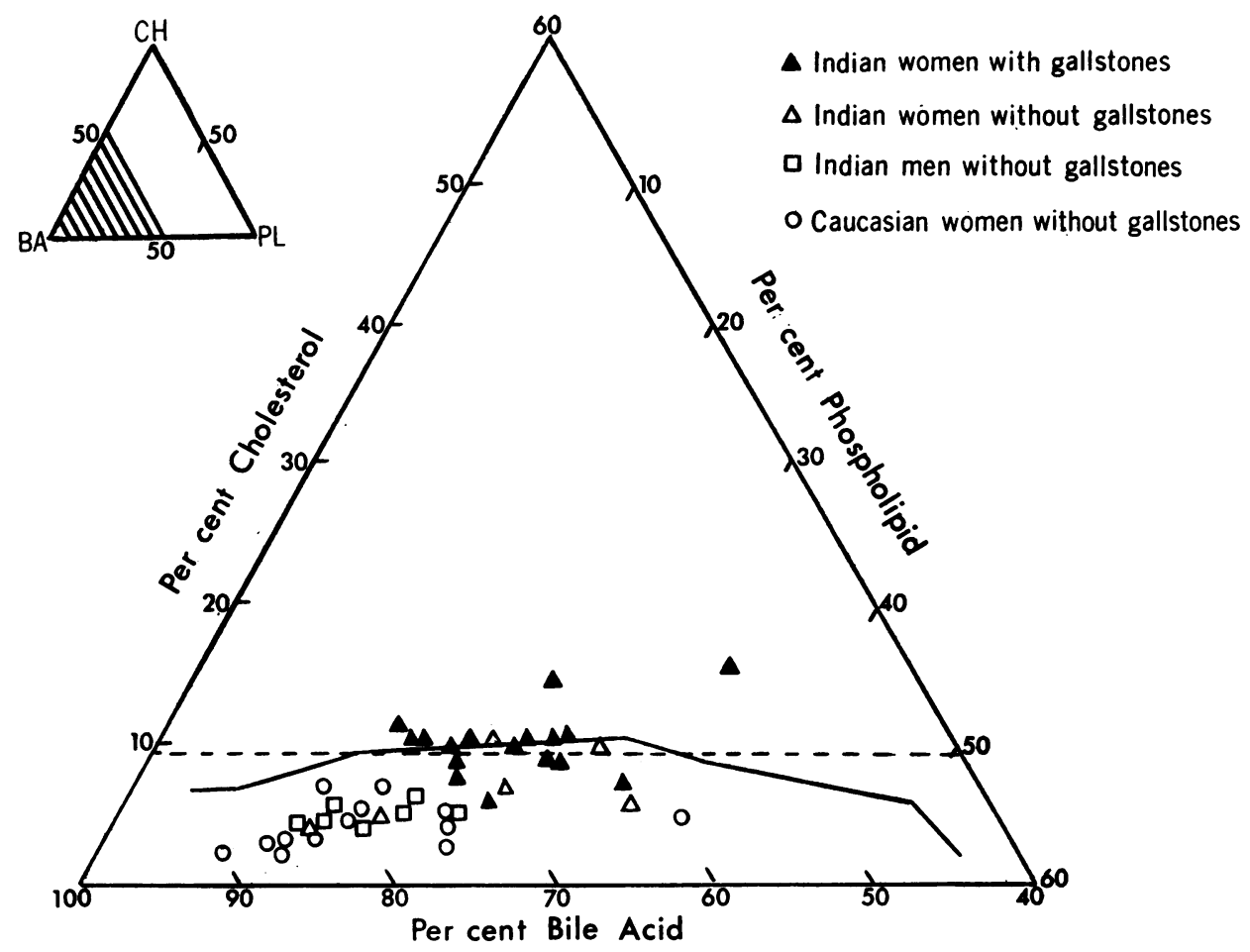

Flgure 1 Bile lipid composition in patients with and without gallstones. Points of composition are plotted on triangular coordinates, as described by Admirand and Small (1). The solid line represents the line of maximum cholesterol solubility. The dashed line indicates a ratio of (bile acids + phospholipids): cholesterol of 10:1. As shown here, compositions from most Indian women with gallstones fell near the line of maximum cholesterol solubility while in most subjects without gallstones, compositions were well below the line.

Average outputs of cholesterol in the gallstone group were not significantly different from those found in Indian women and men without gallstones (Table VIII). However, as compared with Caucasian women without stones, outputs in Indian women with stones were greater to a highly significant degree (means: 47 vs. 29 $\mathrm{mg} / \mathrm{hr}, P<0.01)$. Similar differences were noted when results were normalized according to body weights and surface areas. Even when values were normalized to absolute body weights, there was a difference between Indian women with gallstones, who were more obese, and Caucasian women. However, this difference was ac-

TABLE VIII

Summary of Outputs of Biliary Lipids

\begin{tabular}{|c|c|c|c|c|c|c|}
\hline \multirow[t]{2}{*}{ Subjects } & \multirow[t]{2}{*}{ No. } & \multirow[t]{2}{*}{$\begin{array}{l}\text { Average } \\
\text { age }\end{array}$} & \multicolumn{4}{|c|}{ Cholesterol \pm SEM } \\
\hline & & & $m g / h r$ & $m g / 70 \mathrm{~kg} / \mathrm{hr}$ & $\underset{\mathrm{hr}}{m g / 70 \mathrm{kgI} W^{*} /}$ & $m g / m^{2} / h r$ \\
\hline Indian women with gallstones & 17 & 29 & $47 \pm 4$ & $51 \pm 3$ & $67 \pm 5$ & $29 \pm 2$ \\
\hline Indian women without stones & 6 & 31 & $\begin{array}{l}40 \pm 8 \\
(\mathrm{NS}) \ddagger\end{array}$ & $\begin{array}{c}49 \pm 14 \\
\text { (NS) }\end{array}$ & $\begin{array}{c}62 \pm 20 \\
(\mathrm{NS})\end{array}$ & $\begin{array}{c}25 \pm 6 \\
(\mathrm{NS})\end{array}$ \\
\hline Indian men without stones & 7 & 41 & $\begin{array}{r}48 \pm 7 \\
(\mathrm{NS})\end{array}$ & $\begin{array}{r}41 \pm 6 \\
(\mathrm{NS})\end{array}$ & $\begin{array}{r}51 \pm 8 \\
(\mathrm{NS})\end{array}$ & $\begin{array}{r}25 \pm 3 \\
(\mathrm{NS})\end{array}$ \\
\hline Caucasian women without stones & 12 & 20 & $\begin{array}{c}29 \pm 3 \\
(P<0.01)\end{array}$ & $\begin{array}{c}36 \pm 4 \\
(P<0.01)\end{array}$ & $\begin{array}{c}38 \pm 4 \\
(P<0.001)\end{array}$ & $\begin{array}{c}18 \pm 2 \\
(P<0.001)\end{array}$ \\
\hline
\end{tabular}

* Ideal weight.

$\ddagger \mathrm{NS}=$ not significantly different from Indian women with gallstones.

$\S$ Significantly different from Indian women with gallstones at level shown, according to approximate $t$ test (10). 
centuated by correction to ideal weight and surface area. These latter corrections eliminate the contribution of obesity and variation in body size. Hence, they would seem to give a more accurate estimate of the actual differences.

Bile acid outputs. The average output of bile acids for Indian women with stones was $440 \mathrm{mg} / \mathrm{hr}$. In this group, no correlation existed between outputs and age or gallbladder visualization. The mean value for this group was not significantly different from results of Indian women without stones (440 vs. $551 \mathrm{mg} / \mathrm{hr}$ ). However, bile acid outputs in women with gallstones were distinctly lower than the averages of either Indian men or Caucasian women (means: 440 vs. 1013 and 868 $\mathrm{mg} / \mathrm{hr}$, respectively). When values were normalized, all differences remained significant. Nevertheless, bile acid outputs in Caucasian women varied considerably, and in several subjects, they overlapped those of Indian women.

Phospholipid outputs. No significant differences were found in the uncorrected or normalized outputs of biliary phospholipids between any of the groups.

Lithogenic indices. In 10 of 17 Indian women with gallstones the average LI during the continuous infusion study was 1.0 or greater; in most of the remaining seven patients, bile composition approached the lithogenic range. The mean LI for all the gallstone patients was 1.00 . By contrast, the mean LI in six Indian women without gallstones was 0.67 , and only one subject had lithogenic bile. In Indian men and Caucasian women without stones, no subject secreted lithogenic bile; their mean indices were 0.50 and 0.41 , respectively.

Mean values of bile lipid composition for each patient are plotted on triangular coordinates in Fig. 1; the cholesterol saturation curve, as described by Admirand and Small (1), is superimposed. As shown here, almost all Indian women with gallstones had a biliary lipid composition near or above the line of maximum cholesterol solubility. Indian men and women without gallstones generally had less lithogenic bile; bile composition from Caucasian women without stones was uniformly within the micellar zone.

As shown in Fig. 1, the molar percentage of bile acids in most samples was between 55 and $85 \%$. In this range, the saturation line closely approximates a ratio of (bile acid + phospholipid) : cholesterol of $10: 1$. This $10: 1$ ratio is employed in the following section to demonstrate the interrelations in outputs of the three lipids as they contributed to the production of lithogenic bile.

Outputs of cholesterol vs. bile acids plus phospholipids. In Fig. 2, the hourly outputs of cholesterol are plotted against the sum of the hourly outputs of bile acids and phospholipids; the values are expressed as micromoles per $70 \mathrm{~kg}$ ideal weight per hour. The line at $45^{\circ}$ represents a molar ratio of (bile acids + phospholipids) : cholesterol of $10: 1$. Points above this line would be in the lithogenic zone, as shown in Fig. 1. In most Indian women with gallstones, values fell near or above the lithogenic line. They were almost completely segregated from subjects without stones, whose points fell well below the line. This figure helps to define the relative importance of the secretion rates of cholesterol and bile acids + phospholipids for production of lithogenic bile. For example, average outputs of cholesterol and solubilizing lipids were similar for Indian women with and without gallstones (Table VIII), but four of six subjects without stones were protected from developing lithogenic bile either by relatively low cholesterol outputs or by higher secretion rates of bile acids + phospholipids. In most Indian men, secretion of nonlithogenic bile depended more on a greater output of bile acids than on a low cholesterol output. Nevertheless, secretion rates of cholesterol tended to be lower in men than in women even though averages for the two groups were not significantly different (Table VIII).

in Subjects with and without Gallstones

\begin{tabular}{|c|c|c|c|c|c|c|c|c|}
\hline \multicolumn{4}{|c|}{ Bile acids \pm SEM } & \multicolumn{4}{|c|}{ Phospholipids \pm SEM } & \multirow[t]{2}{*}{$\begin{array}{l}\text { Lithogenic } \\
\text { index } \pm \text { SEM }\end{array}$} \\
\hline$m g / h r$ & $m g / 70 \mathrm{~kg} / \mathrm{hr}$ & $\begin{array}{c}\mathrm{mg} / 70 \mathrm{kgIW} / \\
\mathrm{hr}\end{array}$ & $m g / m^{2} / h r$ & $m g / h r$ & $\begin{array}{c}m g / 70 \mathrm{~kg} / \\
\mathrm{hr}\end{array}$ & $\begin{array}{c}m g / 70 \\
\mathrm{~kg} / \mathrm{IW} / \mathrm{hr}\end{array}$ & $m g / m^{2} / h r$ & \\
\hline $440 \pm 36$ & $477 \pm 35$ & $622 \pm 48$ & $266 \pm 20$ & $228 \pm 23$ & $242 \pm 18$ & $317 \pm 27$ & $136 \pm 12$ & $1.00 \pm 0.1$ \\
\hline $\begin{array}{c}551 \pm 72 \\
(\mathrm{NS})\end{array}$ & $\begin{array}{l}678 \pm 140 \\
(\mathrm{NS})\end{array}$ & $\begin{array}{l}815 \pm 160 \\
(\mathrm{NS})\end{array}$ & $\begin{array}{c}354 \pm 59 \\
(\mathrm{NS})\end{array}$ & $\begin{array}{c}256 \pm 29 \\
(\mathrm{NS})\end{array}$ & $\begin{array}{c}297 \pm 44 \\
(\mathrm{NS})\end{array}$ & $\begin{array}{c}374 \pm 70 \\
(\mathrm{NS})\end{array}$ & $\begin{array}{c}160 \pm 17 \\
(\mathrm{NS})\end{array}$ & $\begin{array}{l}0.67 \pm 0.1 \\
\quad(\mathrm{NS})\end{array}$ \\
\hline $\begin{array}{l}1013 \pm 101 \\
(P<0.01) \S\end{array}$ & $\begin{array}{c}847 \pm 78 \\
(P<0.01)\end{array}$ & $\begin{array}{l}1059 \pm 110 \\
(P<0.01)\end{array}$ & $\begin{array}{c}515 \pm 44 \\
(P<0.01)\end{array}$ & $\begin{array}{c}314 \pm 37 \\
(\mathrm{NS})\end{array}$ & $\begin{array}{c}267 \pm 34 \\
(\mathrm{NS})\end{array}$ & $\begin{array}{c}328 \pm 41 \\
(\mathrm{NS})\end{array}$ & $\begin{array}{l}161 \pm 19 \\
(\mathrm{NS})\end{array}$ & $\begin{array}{c}0.50 \pm 0.1 \\
(P<0.01)\end{array}$ \\
\hline $\begin{array}{c}868 \pm 137 \\
(P<0.05)\end{array}$ & $\begin{array}{l}1114 \pm 196 \\
(P<0.01)\end{array}$ & $\begin{array}{l}1147 \pm 187 \\
(P<0.05)\end{array}$ & $\begin{array}{c}557 \pm 94 \\
(P<0.05)\end{array}$ & $\begin{array}{c}251 \pm 39 \\
(\mathrm{NS})\end{array}$ & $\begin{array}{c}326 \pm 58 \\
(\mathrm{NS})\end{array}$ & $\begin{array}{c}333 \pm 58 \\
(\mathrm{NS})\end{array}$ & $\begin{array}{c}162 \pm 28 \\
(\mathrm{NS})\end{array}$ & $\begin{array}{l}0.41 \pm 0.1 \\
(P<0.01\end{array}$ \\
\hline
\end{tabular}




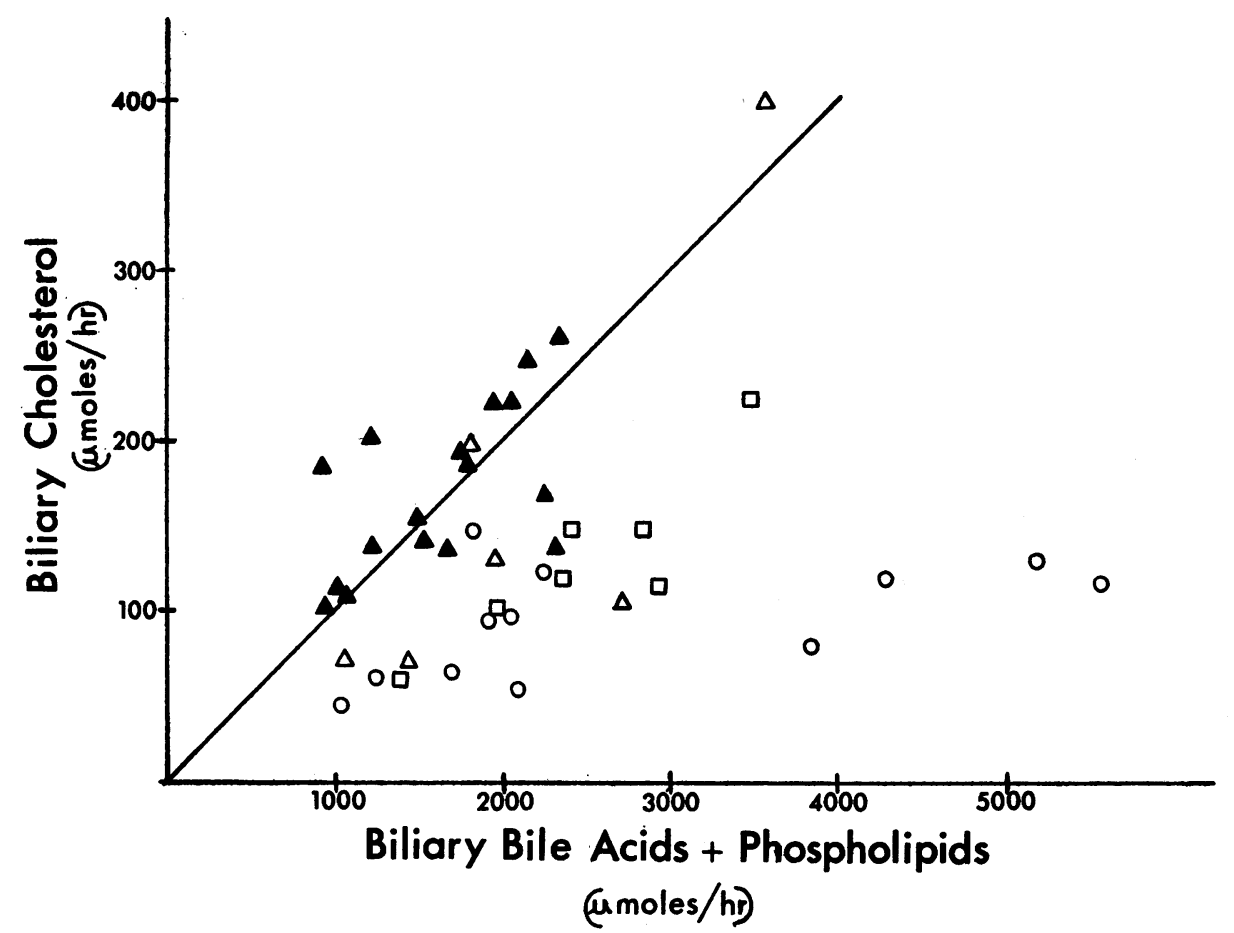

FIGURE 2 Comparison of hepatic secretion rates of cholesterol vs. bile acids + phospholipids. Results are expressed as micromoles per $70 \mathrm{~kg}$ ideal weight per hour. See legend in Fig. 1 for identification of patients. The line at $45^{\circ}$ represents a ratio of (bile acids + phospholipids) : cholesterol of $10: 1$. As shown in Fig. 1, this ratio approximates the line of maximum cholesterol solubility when the molar percentage of bile acids range from 55 to $85 \%$.

In Caucasian women without stones, lithogenic bile was not found in any of the subjects. In several, bile was far outside the lithogenic zone because of a combined low output of cholesterol and high output of bile acids + phospholipids. However, in others, outputs of solubilizing lipids were in the reduced range found in Indian women with stones; in these subjects, bile remained in the micellar zone solely by virtue of low rates of cholesterol secretion. The two Caucasian subjects (B. O. and L. A.), who showed the highest lithogenic indices of the Caucasian group, also had the highest cholesterol outputs. It is of interest that one of these subjects (L. A.) had marked obesity. Although neither had lithogenic bile, their patterns of lipid secretion most resembled those of Indian women with gallstones.

In summary, Fig. 2 shows that lithogenic bile in most Indian women with stones was not due to a change in absolute secretion rate of a single component of bile. Rather, the production of abnormal bile was a function of the relative secretion rates of cholesterol and bile acids + phospholipids. Although secertion rates of solubilizing lipids were clearly reduced in Indian women with gallstones, as compared with Indian men and Caucasian women, their bile would not have been lithogenic if cholesterol outputs had not exceeded the mean value for Caucasian women. Thus, two factors usually contributed to secretion of lithogenic bile by Indian women: (a) a high output of biliary cholesterol, and (b) a low output of solubilizing lipids-bile acids + phospholipids.

Outputs of bile acids vs. cholesterol and phospholipids. In previous studies (17-26), it has been reported that hepatic secretion rates of cholesterol and phospholipids are intimately dependent upon secretion rates of bile acids. This relationship has been attributed to the ability of bile acids to incorporate the other lipids into mixed micelles. Several of these studies in animals have suggested that secretion rates of cholesterol and phospholipids are largely determined by the availability of bile acids and that secretion of biliary lipids occurs in rather fixed ratios. The results of the present study provide data for determining whether hepatic secretions of cholesterol and phospholipids are closely linked to bile acids in man, as suggested by studies in animals. Thus, for all subjects of the present study, average hourly outputs of cholesterol and phospholipids were plotted against outputs of bile acids (Figs. 3 and 4 ).

As shown in Fig. 3, cholesterol and bile acids were not secreted together in a single fixed ratio for all patients. Ratios of cholesterol to bile acids were considerably greater in Indian women with stones than in 


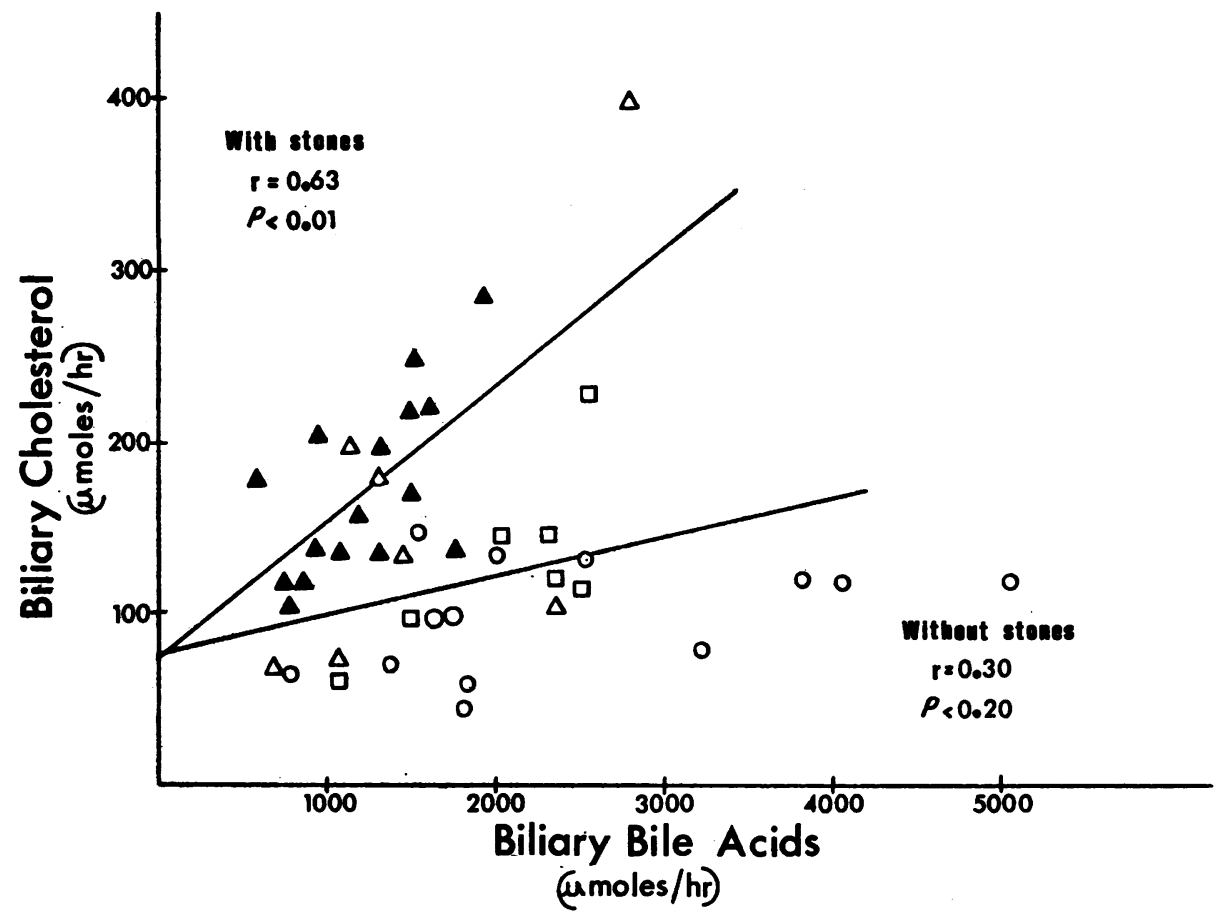

FIGURE 3 Comparison of hepatic secretion rates of cholesterol vs. bile acids. Results are expressed as micromoles per $70 \mathrm{~kg}$ ideal weight per hour. See legend in Fig. 1 for identification of patients. In Indian women with gallstones, there was a significant correlation $(r=$ $0.63, P<0.01$ ) between cholesterol and bile acid outputs. In subjects without stones, no correlation was found $(r=0.30, P<0.20)$.

subjects without stones. Indeed, this secretion of cholesterol independently of bile acids was largely responsible for the production of lithogenic bile in Indian women.

However, in some groups of subjects there was a relationship between cholesterol and bile acid outputs. For example, a positive correlation was observed between outputs of these two lipids in Indian women with stones $(r=0.63, P<0.01)$; at greater bile acid outputs, these women generally secreted more cholesterol. Although values for combined subjects without stones showed no correlation $(r=0.30, P<0.20)$, a significant relationship was found between bile acids and cholesterol within one subgroup, i.e. Indian men $(r=0.85, P<0.02)$. These positive correlations might be explained by a mobilization of more cholesterol into bile due to a greater flux of bile acids through the liver. However, an alternate explanation could be that an increased availability of cholesterol for secretion into bile might also result in an increased production of bile acids. In other words, an increase in available cholesterol in the liver might be the cause of both increases in cholesterol and bile acid outputs.

A significant correlation was noted between outputs of bile acids and phospholipids in subjects both with and without stones (Fig. 4). However, the link between these lipids was not close enough to create a significant decrease in phospholipid outputs in patients with gallstones, as found with bile acids. The data shown in Fig. 4 suggest that Indian women with gallstones continued to secrete relatively normal amounts of phospholipids even when bile acid outputs were diminished. Although a greater secretion of bile acids was associated with larger outputs of phospholipids in these patients, there appeared to be a minimum secretion rate for phospholipids that was maintained despite marked reduction in bile acid outputs.

\section{Cholesterol balance results}

Data for cholesterol balance in seven Indian women with gallstones and seven Indian men without stones are presented in Table IX. Results represent values obtained during the latter days of a 2 wk balance period. All patients received $40 \%$ fat in their diets. Fecal excretions of acidic and neutral steroids and cholesterol balance are presented both as actual values and those normalized to $70 \mathrm{~kg}$ ideal weight.

For Indian women with gallstones, average excretions of acidic steroids corrected to ideal weight, ranged from 168 to $989 \mathrm{mg} /$ day (mean $535 \mathrm{mg} /$ day) ; these values did not differ significantly from those of Indian men without 


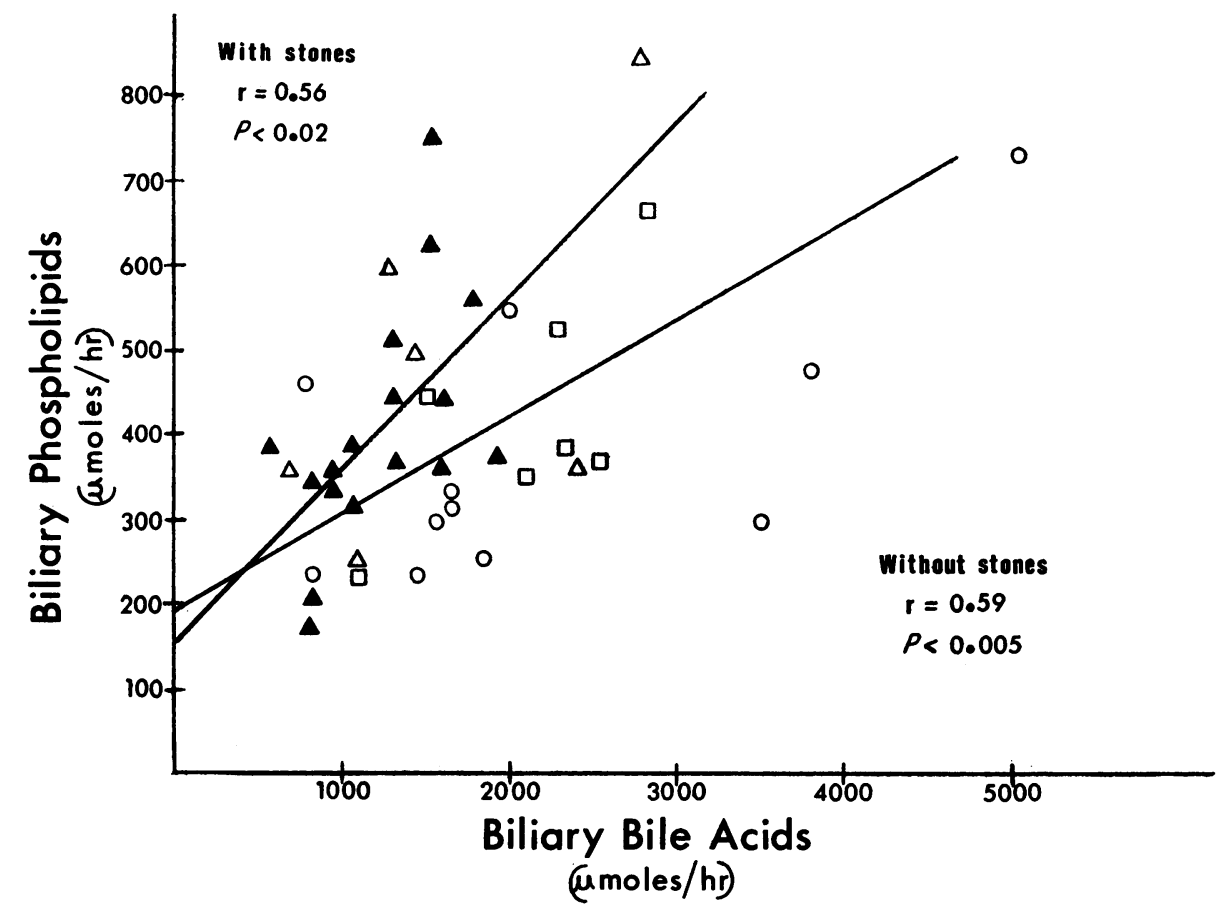

FIGURE 4 Comparison of hepatic secretion rates of phospholipids vs. bile acids. Results are expressed as micromoles per $70 \mathrm{~kg}$ ideal weight per hour. See legend in Fig. 1 for identification of patients. In subjects with and without gallstones, there were significant correlations between outputs of phospholipids and bile acids.

stones (mean $425 \mathrm{mg} /$ day). If we can assume that the subjects were in a metabolic steady state, these values should also equal total daily synthesis of bile acids.

As shown in Table IX, there was no significant difference in fecal neutral steroid excretion between the Indians with and without stones, (mean 1249 vs. $1057 \mathrm{mg}$ / day). The dietary intake of cholesterol for patients in this study averaged about $200 \mathrm{mg}$ /day; since $25-50 \%$ of this cholesterol was probably absorbed (27), fecal excretion of unabsorbed dietary cholesterol should have been in the order of $100-150 \mathrm{mg} / \mathrm{day}$. The remainder of fecal neutral steroids was derived from endogenous cholesterol.

Cholesterol balance equals the difference between cholesterol intake and total fecal steroids. In the steady state, cholesterol balance should approximate cholesterol synthesis. When balance results of this study were normalized to ideal weights, no significant differences were found between Indian men and women.

\section{DISCUSSION}

The purpose of this study was to examine the metabolic abnormalities responsible for the production of lithogenic bile in American Indian women with gallstones. For this purpose, we have employed an intubation technique recently developed for estimating hepatic secretions of biliary lipids in man (5). Three groups of sub- jects, who were without gallstones, served as controls. However, even these control subjects might be considered at risk for eventual gallstone formation. Indian women without stones are particularly prone to development of the disease (6). Among Indian men and Caucasian women, gallstones occur less often than in Indian women, but they are found more frequently than in Caucasian men $(6,28-30)$. Therefore, in comparing hepatic secretion rates, the "normal" or ideal patterns of lipid secretion may not have been adequately defined. Nonetheless, differences between subjects with and without stones were clearly evident; and in our view, these differences were sufficient to delineate the major abnormalities in hepatic secretion of lipids that induce lithogenic bile in patients with gallstones.

In addition to the intubation procedure, cholesterol balance studies were carried out in Indian women with gallstones and in Indian men. Excretions of neutral and acidic steroids were essentially the same for the two groups. Therefore, for further comparison, we have summarized in Table $\mathrm{X}$ mean values reported in previous balance studies for groups of non-Indian patients without gallstones. Results from all studies were obtained by the same sterol balance techniques, i.e. by those developed by Grundy, Ahrens, and associates (12-14). Values are given only for groups of patients who received approxi- 
TABLE IX

Cholesterol Balance Data in Indian Subjects

\begin{tabular}{|c|c|c|c|c|c|c|c|c|c|c|}
\hline \multirow[b]{2}{*}{ Subjects } & \multirow{2}{*}{$\begin{array}{l}\text { Collection } \\
\text { period }\end{array}$} & \multirow{2}{*}{$\begin{array}{l}\text { Cholesterol } \\
\text { intake }\end{array}$} & \multicolumn{4}{|c|}{ Fecal steroids } & \multicolumn{4}{|c|}{ Fecal steroids } \\
\hline & & & Acidic & Neutral & Total & Balance & Acidic & Neutral & Total & Balance \\
\hline & days & $m g / d a y$ & \multicolumn{2}{|c|}{$m g / d a y$} & \multicolumn{2}{|c|}{$m g / d a y$} & \multicolumn{4}{|c|}{$m g / 70 \mathrm{kgIW} / \mathrm{day}$} \\
\hline \multicolumn{11}{|c|}{ Indian women with gallstones } \\
\hline L. E. & 5 & 158 & 820 & 1121 & 1941 & 1783 & 989 & 1352 & 2342 & 2152 \\
\hline S. H. & 4 & 180 & 400 & 1138 & 1538 & 1358 & 518 & 1477 & 1996 & 1763 \\
\hline A. $\mathbf{P}$. & 8 & 135 & 120 & 665 & 785 & 650 & 168 & 931 & 1099 & 910 \\
\hline W. J. & 5 & 180 & 265 & 973 & 1238 & 915 & 343 & 1075 & 1419 & 1186 \\
\hline R. H. & 4 & 137 & 410 & 693 & 1103 & 966 & 531 & 898 & 1429 & 1249 \\
\hline M. B. & 6 & 157 & 438 & 674 & 1112 & 955 & 567 & 873 & 1441 & 1241 \\
\hline L. W. & 4 & 200 & 449 & 1526 & 1975 & 1775 & 628 & 2136 & 2765 & 2525 \\
\hline \multicolumn{11}{|l|}{ Mean } \\
\hline 土SEM & $5.1 \pm 0.6$ & $164 \pm 9$ & $415 \pm 81$ & $970 \pm 121$ & $1384 \pm 170$ & $1200 \pm 168$ & $535 \pm 96$ & $1249 \pm 172$ & $1784 \pm 227$ & $1575 \pm 223$ \\
\hline \multicolumn{11}{|c|}{ Indian men without gallstones } \\
\hline L. P. & 5 & 210 & 220 & 1076 & 1296 & 1086 & 233 & 1140 & 1.373 & 1151 \\
\hline A. $\mathbf{M}$. & 9 & 198 & 554 & 1083 & 1637 & 1442 & 520 & 1018 & 1538 & 1355 \\
\hline F. S. & 6 & 202 & 362 & 1600 & 1962 & 1760 & 362 & 1600 & 1962 & 1760 \\
\hline A. Mo. & 4 & 225 & 430 & 540 & 970 & 745 & 455 & 572 & 1028 & 789 \\
\hline E. S. & 4 & 232 & 538 & 635 & 1173 & 941 & 500 & 590 & 1090 & 873 \\
\hline E. S. D. & 5 & 285 & 625 & 1085 & 1710 & 1410 & 543 & 943 & 1487 & 1226 \\
\hline J. D. & 4 & 206 & 331 & 1385 & 1716 & 1500 & 367 & 1537 & 1904 & 1665 \\
\hline \multicolumn{11}{|l|}{ Mean } \\
\hline 土ȘEM & $5.2 \pm 0.7$ & $223 \pm 11$ & $437 \pm 54$ & $1058 \pm 142$ & $1495 \pm 134$ & $1269 \pm 135$ & $425 \pm 42$ & $1057 \pm 154$ & $1483 \pm 137$ & $1260 \pm 139$ \\
\hline
\end{tabular}

* All subjects were on cholesterol balance study for at least $2 \mathrm{wk}$; throughout this period, $40 \%$ fat diets (Table IV) and internal markers-chromic oxide and $\beta$-sitosterol.

mately $40 \%$ of dietary calories as fat. Patients from these lesterolemia, $(c)$ hypertriglyceridemia, and $(d)$ normoprevious studies were classified in the following categor- lipidemia with obesity. Although it seems unlikely that ies: (a) normolipidemia without obesity, $(b)$ hypercho- a valid statistical comparison could be made between

TABLE X

Summary of Cholesterol Balance Data in Indian and Non-Indian Subjects

\begin{tabular}{|c|c|c|c|c|c|c|c|c|c|c|}
\hline \multirow[b]{2}{*}{ Authors } & \multirow[b]{2}{*}{ Reference } & \multirow[b]{2}{*}{ Diagnosis } & \multirow{2}{*}{$\begin{array}{l}\text { No. of } \\
\text { patients }\end{array}$} & \multirow[b]{2}{*}{ Sex } & \multirow{2}{*}{$\begin{array}{c}\text { Age } \\
\text { range }\end{array}$} & \multirow{2}{*}{$\begin{array}{c}\text { Average } \\
\text { per cent } \\
\text { ideal } \\
\text { body wt }\end{array}$} & \multicolumn{3}{|c|}{ Fecal steroids } & \multirow{2}{*}{$\begin{array}{c}\text { Choles- } \\
\text { terol } \\
\text { balance }\end{array}$} \\
\hline & & & & & & & Acidic & Neutral & Total & \\
\hline & & & & & & & \multicolumn{3}{|c|}{$m g / 70 \mathrm{kgIW} / \mathrm{day}$} & $\begin{array}{c}m g / 70 \\
k g / d a y\end{array}$ \\
\hline \multicolumn{11}{|l|}{ Indians } \\
\hline Present study & & Gallstones & 7 & F & $24-53$ & 121 & 535 & 1249 & 1784 & 1240 \\
\hline Present study & & Normal & 7 & $\mathbf{M}$ & $22-63$ & 126 & 425 & 1057 & 1483 & 1000 \\
\hline \multicolumn{11}{|l|}{ Non-Indians } \\
\hline Grundy et al. & $27,31-34$ & Normal & 6 & M-F & $41-71$ & 110 & 247 & 697 & 941 & 853 \\
\hline Connor et al. & 35 & Normal & 6 & M & $36-44$ & 108 & 341 & 438 & 779 & 720 \\
\hline Miettinen & 36 & Normal & 10 & M-F & $23-46$ & 96 & 259 & 698 & 957 & 868 \\
\hline Grundy et al. & $27,31-34$ & Hypercholesterolemia & 15 & $\mathrm{~F}$ & $21-72$ & 106 & 294 & 690 & 984 & 908 \\
\hline Grundy et al. & $27,31-34$ & Hypercholesterolemia & 10 & $\mathbf{M}$ & $28-61$ & 102 & 243 & 589 & 832 & 833 \\
\hline Grundy et al. & $27,31-34$ & Hypertriglyceridemia & 4 & $\mathrm{~F}$ & $36-59$ & 110 & 380 & 706 & 1086 & 1038 \\
\hline Grundy et al. & $27,31-34$ & Hypertriglyceridemia & 7 & M & $39-54$ & 109 & 538 & 816 & 1355 & 1190 \\
\hline Miettinen & 35 & Hypertriglyceridemia & 10 & M-F & $34-57$ & 127 & 326 & 932 & 1258 & 910 \\
\hline Miettinen & 36 & Obesity & 4 & $\mathrm{~F}$ & $26-63$ & 185 & 464 & 1651 & 2115 & 1092 \\
\hline Miettinen & 36 & Obesity & 6 & $\mathbf{M}$ & $24-58$ & 159 & 488 & 1216 & 1704 & 1008 \\
\hline Nestel & * & Obesity & 8 & M-F & $26-59$ & 231 & 737 & 1675 & 2412 & 870 \\
\hline
\end{tabular}

* Personal communication. 
TABLE XI

Approximation of Bile Acid Reabsorption in Subjects with and without Gallstones

\begin{tabular}{cccc}
\hline Subject & $\begin{array}{c}\text { Biliary bile } \\
\text { acids }\end{array}$ & $\begin{array}{c}\text { Fecal bile } \\
\text { acids }\end{array}$ & $\begin{array}{c}\text { Reabsorp- } \\
\text { tion }\end{array}$ \\
\hline$m g / 70 \mathrm{~kg} \mathrm{IW} /$ day & $\%$
\end{tabular}

Indian women with gallstones

$\begin{array}{lrrr}\text { L. E. } & 12,000 & 989 & 91 \\ \text { S. H. } & 13,400 & 518 & 96 \\ \text { W. J. } & 15,000 & 343 & 98 \\ \text { R. H. } & 6,720 & 531 & 92 \\ \text { S. N.* } & 12,500 & 442 & 97 \\ \text { C. P.* } & 3,700 & 234 & 94 \\ \text { L. W. } & 8,900 & 628 & 92\end{array}$

Average 94

Indian men without gallstones

$\begin{array}{llll}\text { A. M. } & 15,400 & 529 & 97 \\ \text { E. S. } & 10,400 & 500 & 95 \\ \text { L. P. } & 15,300 & 233 & 98 \\ \text { A. Mo. } & 11,500 & 455 & 96\end{array}$

Average 97

* Patients S. N. and C. P. received a diet containing $5 \%$ of calories as fat throughout $2 \mathrm{wk}$ balance study and at a time of intubation. The results of their studies are not reported in other tables. Average outputs of biliary bile acids during 14-hr studies were $780 \pm 317$ and $234 \pm 148 \mathrm{mg} / 70 \mathrm{~kg}$ ideal wt per $\mathrm{hr} \pm \mathrm{SD}$, respectively. Excretions of fecal bile acids are the average of 5- and 7-day collections at the end of the balance period.

results of these different groups, the findings should provide us with a perspective for interpretation of balance results in Indian patients.

The present study strongly supports the concept that cholesterol gallstones in American Indians are secondary to abnormal or lithogenic bile. Since bile obtained under the conditions of our studies was mainly hepatic and not gallbladder bile, we have confirmed that lithogenic bile in Indian women with gallstones originated in the liver, as proposed by Small and Rapo (2). Also, lithogenic bile in patients with stones was usually the result of two factors, namely, a decreased hepatic secretion of bile acids and a concomitant increase in secretion of cholesterol. These alterations could have been related to at least three aspects of cholesterol and bile acid metabolism: (a) reabsorption of bile acids, $(b)$ synthesis of bile acids, and $(c)$ synthesis of cholesterol. In this discussion, we will attempt to evaluate the importance of abnormalities in each of these parameters for the production of lithogenic bile in Indian women.

Reabsorption of bile acids. The reduced rate of hepatic secretion of bile acids in Indian women with gallstones is almost certainly linked to a decreased pool size of bile acids, as reported by Vlahcevic and associates $(3,4)$.
One explanation for a decreased pool size could be a reduction in intestinal reabsorption of bile acids. If losses of bile acids were to exceed the patients' capacity to increase bile acid synthesis, a decreased pool size would result. Such a mechanism may explain the increased prevalence of gallstones in patients with major ileal resection (37). Since bile acids are absorbed almost exclusively in the ileum (38), removal of this segment of intestine produces a severe defect in their reabsorption along with a marked increase in their excretion (39). Hence, the postileectomy state could represent one model for gallstone formation, and we can ask whether the decreased hepatic secretion of bile acids found in Indian women with stones might be explained by a defect in bile acid reabsorption.

Intestinal losses of acidic steroids in Indian women with gallstones was not significantly greater than in Indian men without stones; therefore, these women apparently do not have a severe defect in bile acid reabsorption that could entirely account for their gallstones. However, excretions in both women and men appeared somewhat higher than reported previously in non-Indian subjects without gallstones (Table $\mathrm{X}$ ). Since the total flux of bile acids through the enterohepatic circulation was reduced in Indian women, an elevated or even normal fecal excretion of bile acids would reflect a reduced percentage reabsorption. Thus, in Table XI, we have attempted to estimate the percentage of bile acid reabsorption in subjects with and without stones. Our estimate was based on the assumption that the rate of hepatic secretion of bile acids equals the rate of delivery of bile acids to the lower intestinal tract. The following equation was used for calculation:

$$
\begin{aligned}
& \text { Bile acid reabsorption }(\%)=100 \times[\text { biliary } \\
& \text { output of bile acids }(\mathrm{mg} / \text { day })-\text { fecal excretion } \\
& \text { of bile acids }(\mathrm{mg} / \text { day })] \div \text { biliary output of bile } \\
& \text { acids }(\mathrm{mg} / \text { day }) \text {. }
\end{aligned}
$$

Outputs of biliary bile acids were estimated during constant infusion of liquid formula over periods of several hours, and they probably do not correspond precisely to biliary outputs during normal dietary intakes. Nevertheless, in order to approximate reabsorption and to make comparisons, we have assumed that, in all patients, bile acids were secreted into the intestinal tract for $16 \mathrm{hr} /$ day at the rate observed during the infusion study and that they were sequestered in the gallbladder during the remaining $8 \mathrm{hr}$. Thus, daily inputs of bile acids into the intestinal tract were approximated by multiplying the average hourly output by 16 . In seven Indian women with gallstones, reabsorption ranged from 91 to $98 \%$ (mean 94\%); this mean value was lower than those found for 4 Indian men without stones (97\%). Although the differences were not great, percentages of bile acid 
reabsorption in Indian women with stones tended to be lower than those in men without stones, and thus our patients with gallstones may have had a relative decrease in bile acid reabsorption.

This finding does not necessarily imply that Indian women with gallstones have a mucosal defect in bile acid reabsorption. Such a defect might exist, but other factors could also account for a reduced percentage absorption. For example: $(a)$ passage of intestinal contents through the ileum might be more rapid in Indian women; $(b)$ bile acids might be removed at a fixed rate by adsorption to intraluminal contents; and $(c)$ the colonic phase of reabsorption might be altered by increased conversion of primary into secondary bile acids. At the present time, we cannot differentiate between these possibilities, and more studies will be necessary to determine whether a reduction in percentage absorption in Indian women with gallstones is due to a true defect in reabsorption or simply to a fixed excretion of bile acids resulting from physiological factors.

Although a decrease in bile acid reabsorption may have contributed to a depletion of bile acids in Indian women with gallstones, we question whether the observed reduction in hepatic secretion of bile acids can be adequately explained by this mechanism alone. There is considerable evidence that normal subjects, who are non-Indian, can compensate for moderately great losses of bile acids without reduction in pools or development of lithogenic bile and gallstones. This is best exemplified by results obtained with the bile-acid binding agent, cholestyramine. During administration of cholestyramine to non-Indian subjects, fecal losses of bile acids exceed by many-fold those found in Indian women of this study (39). Yet, there are no indications that cholestyramine causes extreme abnormalities in bile lipid composition such as observed in Indian women with gallstones. For example, Dam, Krogh Jensen, Kallehauge, and Fenger (40) studied the ratio of total bile acids to cholesterol in bile obtained from duodenal aspirates in seven normal subjects before and after $6 \mathrm{wk}$ of cholestyramine treatment. In almost all subjects this ratio was reduced somewhat after $6 \mathrm{wk}$ of treatment, but marked reductions were exceptional. Wood, Shioda, Estrich, and Splitter (41) likewise studied the influence of cholestyramine treatment on lithogenicity of bile in four obese normolipidemic subjects. These workers found no increased lithogenicity throughout a $4 \mathrm{wk}$ period of drug treatment, as compared to pretreatment values. Also, Kenney and Garbutt (42) observed no significant reduction in pool sizes of total bile acids in six normal subjects given cholestyramine for 5-6 wk. Finally, there have been no reports of increased cholelithiasis secondary to cholestyramine treatment. Fuson (personal communication) has followed 52 patients during $6 \mathrm{yr}$ of cholestyramine therapy, and none of them have developed any symptoms of biliary tract disease or gallstones. Considering these observations together, it appears that cholestyramine does not cause a depletion of bile acids of the magnitude found in Indian women with gallstones; and therefore, the marked reduction in hepatic secretion of bile acids in our patients must be explained in large part by mechanisms other than defective reabsorption.

Bile acid synthesis. Since bile acids are continuously lost from the enterohepatic circulation by fecal excretion, the pool must be constantly replenished by new synthesis in the liver. The control of bile acid synthesis depends largely on feedback inhibition mediated by bile acids $(43,44)$. Thus, the size of the bile acid pool is determined by the balance between synthesis and reabsorption. When reabsorption is reduced, synthesis must increase to prevent depletion of bile acid pools. Once a steady state is established, bile acid synthesis equals excretion.

As discussed above, normal persons can compensate for moderate defects in bile acid reabsorption without a reduction in pools. In contrast, Indian women, whose defect in reabsorption of bile acids is only slight at most, are unable to maintain pools at adequate levels by increased synthesis. Therefore, it would appear that the major cause of bile acid deficiency in these patients is a defective regulation of bile acid synthesis. In a sense, feedback inhibition of bile acid synthesis would seem to be overly active in these patients; that is, bile acid synthesis is inhibited at a lower rate of bile acid return than in normal persons. Consequently pool sizes and hepatic secretion rates of bile acids are reduced.

Factors regulating the conversion of cholesterol into bile acids at a molecular level have not been entirely elucidated. Apparently the $7 \alpha$-hydroxylation of cholesterol is the rate-limiting step, and the rate of this reaction is partially controlled by bile acids (44). Whether the control of this particular reaction is defective in patients with gallstones remains to be determined.

Synthesis of cholesterol. In most Indian women with gallstones, hepatic secretion rates of cholesterol were found to be increased. Few patients would have produced lithogenic bile if cholesterol output had not significantly exceeded the mean for Caucasian women. In several Caucasian women, secretion rates of bile acids were as low as those of Indian women, but their bile remained in the micellar zone because of low outputs of cholesterol.

High secretion rates of biliary cholesterol in Indian women with gallstones may be related to an increased availability of cholesterol in the liver. This excess hepatic cholesterol could result from increased cholesterol production. Such an increase in cholesterol synthesis is suggested for Indian women by the balance data reported in Table $\mathrm{X}$. When values were normalized 
to ideal weight, Indian women with stones were shown to excrete about twice the quantity of fecal steroids as non-Indian subjects from other studies. It seems unlikely that this marked difference between Indian women and non-Indians can be explained simply by differences in balance technique or diet. Essentially the same methods were used in all studies, and both normal subjects and Indian women received $40 \%$ of dietary calories as fat. Among normal non-Indian subjects, average values for steroid excretion and cholesterol balance were comparable whether they were fed liquid formula (31-35) or solid food diets (36); thus, there seems to be little possibility that the mixed solid food-formula diet given to Indian women in this study could account for their high excretion of fecal steroids. Additional comparison with a sizable number of hyperlipidemic patients fed both formula (31-35) and solid food (36) further confirms the existence of an abnormally high output of fecal steroids in Indian women with gallstones. Most of the increment in steroid excretion in Indian women was found in the neutral steroid fraction; this excess neutral steroid was probably derived in large part from the increased biliary cholesterol that was observed in these women.

An increased cholesterol synthesis in Indian women might be partially explained by obesity. Apparently, synthesis of cholesterol is proportional to total body weight, and therefore is increased in obesity $(36,45)$. As shown in Table $\mathrm{X}$, when results were corrected to ideal weight, fecal excretions of steroids in obese subjects greatly exceeded those of normal. However, when cholesterol balance, which should approximate cholesterol synthesis, was expressed per unit of total body weight, values for normal and obese subjects became comparable. Both Indian women and men of this study were inclined to obesity, and their steroid excretion patterns resembled those of obese subjects from other studies. As shown by correction of cholesterol balance data to $70 \mathrm{~kg}$ total body weight, a portion of the greater cholesterol synthesis found in Indian women can be explained by obesity. Therefore, we have concluded that obesity is at least partially responsible for their increased secretion of biliary cholesterol.

However, the cholesterol balance data shown in Table $\mathrm{X}$ suggests that cholesterol synthesis in Indian women with stones may still be greater than normal after correction for obesity. Although carefully controlled studies will be required to resolve this point, we can speculate as to whether factors other than obesity might also contribute to increased cholesterol synthesis in Indian women with stones. A greater synthesis might simply represent a constitutional characteristic of Indians, but it might also be related to bile acid metabolism. Cholesterol synthesis in the intestine, and possibly in the liver, is under feedback inhibition by bile acids (46-49). Thus, decreased recirculation of bile acids in Indian women may further enhance cholesterol synthesis in these two sites and thereby increase the secretion of biliary cholesterol.

An alternate explanation for the increased biliary cholesterol in gallstone patients might be an unusually rapid clearance of cholesterol from the hepatic cell into bile. In this case, less cholesterol would be available for conversion into bile acids. Similarly, the rapid removal of cholesterol from the liver, by releasing feedback inhibition, could further stimulate cholesterol synthesis. Such a mechanism could account for most of the alterations of biliary lipids found in patients with gallstones.

Recently, Shaffer, Braasch, and Small (50) reported that lithogenic bile is transformed to normal in many Caucasian patients after cholecystectomy. This finding suggests that the presence of the gallbladder in the enterohepatic circulation may affect the secretion of biliary lipids. It might therefore be questioned whether a diseased gallbladder could be the cause rather than the effect of lithogenic bile and abnormal rates of lipid secretion in Indian women with stones. In our view, this possibility is unlikely for several reasons. First, Indian women without gallstones also showed relatively abnormal secretion rates of biliary lipids, as compared with Caucasian women (Table VIII). Second, Thistle and Schoenfield (51) have reported that young Chippewa Indian women without gallstones have a high prevalence of lithogenic bile, and in unpublished studies from our laboratory, ${ }^{1}$ we have also shown that a high percentage of young teenage Indian women, who are without stones, have abnormal bile. And thirdly, studies carried out several months after cholecystectomy in 6 of our 17 Indian women with gallstones revealed no correction of their previous abnormalities in lipid secretion. ${ }^{2}$ Lithogenic bile in Indian women with gallstones, in contrast to Caucasian patients, was not transformed to normal by cholecystectomy. These findings do not support the view that lithogenic bile in Indian patients is the result of gallstones and biliary tract disease. Rather, they suggest that production of lithogenic bile is due to more generalized abnormalities in the metabolism of cholesterol and bile acids.

Whatever the mechanisms for regulation of sterol metabolism, human beings in general, and particularly Indian women with gallstones, seem to have an unfavorable balance between biliary secretion of cholesterol and bile acid formation. In a recent report, Quintao, Grundy, and Ahrens (27) showed that when

\footnotetext{
${ }^{1}$ Metzger, A. L., R. Adler, and S. M. Grundy. Unpublished data.
} 
dietary cholesterol is fed and absorbed in excessive amounts, reexcretion of this cholesterol occurs in the form of neutral sterol; there is no increased conversion of cholesterol into bile acids. In this regard, man differs from animals such as the $\operatorname{dog}$ (52) and rat (53); in these latter species, cholesterol feeding causes a definite increase in bile acid excretion. In comparison to animals, man excretes more sterol as cholesterol and less as bile acids. This difference is particularly apparent in Indian women with gallstones.

In conclusion, lithogenic bile in Indian women with gallstones may be related to abnormalities in reabsorption of bile acids as well as to excessive synthesis and hepatic secretion of cholesterol. However, in our view, the key abnormality is a defective regulation of bile acid synthesis. A relatively minor defect in bile acid reabsorption, as seen in Indian women with gallstones, would not deplete bile acid pools in normal subjects; yet, in Indian women, who fail to respond with increased synthesis, a small defect in reabsorption may significantly reduce bile acids in the enterohepatic circulation. Likewise, increased production of cholesterol would not enhance biliary cholesterol if the excess cholesterol were rapidly converted into bile acids, as occurs in several animal species. Therefore, a limited capacity for transformation of cholesterol into bile acids markedly accentuates the significance of other abnormalities in sterol metabolism.

Whether lithogenic bile in non-Indian patients with gallstones can be explained by the same mechanisms remains to be proven. Presumably, in ileectomy patients, a severe defect in reabsorption of bile acids alone may deplete the bile acid pool and result in lithogenic bile. On the other hand, in extreme obesity, a greater cholesterol synthesis per se might increase the cholesterol content of bile to the point of supersaturation. However, on the basis of the present study, we suggest that combined defects in bile acid and cholesterol secretion would be required for the production of lithogenic bile in otherwise normal persons. In several Caucasian women of this study, secretion rates of bile acids were relatively low, but they were protected from lithogenic bile by low cholesterol outputs. Since Indian men consistently had higher secretions of bile acids, we might speculate as to whether many Caucasian as well as Indian women do not have relatively small pools of bile acids. If so, they might become susceptible to gallstone formation under conditions that would increase cholesterol output, such as increasing weight. Indeed, our studies offer a reasonable explanation of the relation between obesity and cholesterol gallstones (29). If the excess cholesterol produced in obesity is not converted into bile acids, biliary cholesterol should be increased, and if the bile acid pool is already reduced, lithogenicity of bile should become high. Thus one approach for reducing the cholesterol content of bile, and its lithogenicity, might be weight reduction; in this regard, Miettinen (36) has shown that obese patients produce less cholesterol after losing weight.

A second approach to converting lithogenic into normal bile is to enhance the production of bile acids. This method had been utilized by Redinger and Small (54) who demonstrated in monkeys that the synthesis and hepatic secretion of bile acids can be increased by phenobarbital administration. Although future investigations may reval new techniques for increasing bile acid synthesis, the most effective means available today for expanding the bile acid pool is by oral administration of bile acids (51). As demonstrated by Danzinger, Hofmann, Schoenfield, and Thistle (55), the prolonged administration of one primary bile acid, chenodeoxycholic acid, can transform lithogenic into normal bile, and gallstones may be dissolved or reduced in size.

\section{ACKNOWLEDGMENTS}

We are grateful to Miss Marjorie Whelan, Mrs. Margaret Hendrikx, and others of the nursing and dietetic services of this Section for their assistance in this project. Excellent technical assistance was provided by $\mathrm{Mr}$. James Hobza, Mr. Elliott Groszek, Mr. Robert Collins, and Mr. Howard Hughes. We also thank Dr. Eunice Flock for biochemical assistance. Finally, the authors are grateful to the Indian Health Service and the Phoenix Indian Medical Center for their cooperation in this study.

\section{REFERENCES}

1. Admirand, W. H., and D. M. Small. 1968. The physicochemical basis of cholesterol gallstone formation in man. J. Clin. Invest. 47 : 1043.

2. Small, D. M., and S. Rapo. 1970. Source of abnormal bile in patients with cholesterol gallstones. N. Engl. J. Med. 283 : 53.

3. Vlahcevic, Z. R., C. C. Bell, Jr., I. Buhac, J. T. Farrar, and L. Swell. 1970. Diminished bile acid pool size in patients with gallstones. Gastroenterology. 59: 165.

4. Vlahcevic, Z. R., C. C. Bell, Jr., D. H. Gregory, G. Buker, P. Juttijudata, and L. Swell. 1972. Relationship of bile acid pool size to the formation of lithogenic bile in female Indians of the Southwest. Gastroenterology. $62: 73$.

5. Grundy, S. M., and A. L. Metzger. 1972. A physiologic method for estimation of hepatic secretion of biliary lipids in man. Gastroenterology. 62: 1200.

6. Sampliner, R. E., P. H. Bennett, L. J. Comess, F. A. Rose, and T. A. Burch. 1970. Gallbladder disease in Pima Indians. N. Engl. J. Med. 283: 1358.

7. Metropolitan Life Insurance Company Statistical Bulletin 40 (November-December 1959): New Weight Standards for Men and Women. New York.

8. Reid, J. M., S. D. Fullmer, K. D. Pettigrew, T. A. Burch, P. H. Bennett, M. Miller, and G. D. Whedon. 1971. Nutrient intake of Pima Indian women: relationships to diabetes mellitus and gallbladder disease. $\mathrm{Am}$. J. Clin. Nutr. 24 : 1281. 
9. Ahrens, E. H., Jr., 1970. The use of liquid formula diets in metabolic studies: 15 years' experience. $A d v$. Metab. Disord. 4 : 297.

10. Ostle, B. 1963. Statistics in Research. Iowa State University Press, Ames. Second edition. 120.

11. Metzger, A. L., S. Heymsfield, and S. M. Grundy. 1972. The lithogenic index: a numerical expression for the relative lithogenicity of bile. Gastroenterology. 62: 499.

12. Grundy, S. M., E. H. Ahrens, Jr., and T. A. Miettinen. 1965. Quantitative isolation and gas-liquid chromatographic analysis of fecal bile acids. J. Lipid Res. 6: 397.

13. Miettinen, T. A., E. H. Ahrens, Jr., and S. M. Grundy. 1965. Quantitative isolation and gas-liquid chromatographic analysis of dietary and fecal neutral steroids. J. Lipid Res. $6: 411$.

14. Grundy, S. M., E. H. Ahrens, Jr., and G. Salen. 1968. Dietary $\beta$-sitosterol as an internal standard to correct for cholesterol losses in sterol balance studies. J. Lipid Res. 9 : 374.

15. Davignon, J., W. J. Simmonds, and E. H. Ahrens, Jr. 1968. Usefulness of chromic oxide as an internal standard for balance studies in formula fed patients and for assessment of colonic function. J. Clin. Invest. 47: 127.

16. DuBois, D., and E. F. DuBois. 1916. Clinical calorimetry. X. A formula to estimate the approximate surface area if height and weight be known. Arch. Intern. Med. $17: 863$.

17. Thompson, J. C., and H. M. Vars. 1953. Biliary excretion of cholic acid and cholesterol in hyper, hypo, and euthyroid rats. Proc. Soc. Exp. Biol. Med. 83: 246.

18. Eriksson, S. 1957. Biliary excretion of bile acids and cholesterol in bile fistula rats: bile acids and steroids. Proc. Soc. Exp. Biol. Med. 94: 578.

19. Kay, R. E., and C. Entenman. 1961. Stimulation of taurocholic acid synthesis and biliary excretion of lipids. Am. J. Physiol. 200 : 855.

20. Thureborn, E. 1962. Human hepatic bile. Acta Chir. Scand. Suppl. 303: 1 .

21. Swell, L., C. C. Bell, and C. Entenman. 1968. Bile acids and lipid metabolism. III. Influence of bile acids on phospholipids in liver and bile of the isolated perfused dog liver. Biochim. Biophys. Acta. 164: 278.

22. Nilsson, S., and T. Schersten. 1969. Importance of bile acids for phospholipid secretion into hepatic bile. Gastroenterology. 57 : 525 .

23. Hardison, W. G. M., and T. I. Francis. 1969. The mechanism of cholesterol and phospholipid excretion in bile. Gastroenterology. 56: 1164. (Abstr.)

24. Dowling, R. H., E. Mack, and D. M. Small. 1971. Biliary lipid secretion and bile composition after acute and chromic interruption of the enterohepatic circulation in the rhesus monkey. IV. Primate biliary physiology. J. Clin. Invest. 50: 1917.

25. Balint, J. A., D. A. Beeler, E. C. Kyriakides, and D. H. Treble. 1971. The effect of bile salts upon lecithin synthesis. J. Lab. Clin. Med. 77: 122.

26. Wheeler, H. O., and K. K. King. 1972 Biliary excretion of lecithin and cholesterol in the dog. J. Clin. Invest. $51: 1337$.

27. Quintao, E., S. M. Grundy, and E. H. Ahrens, Jr. 1971. Effects of dietary cholesterol on the regulation of total body cholesterol in man. J. Lipid Res. 12: 233.

28. Ingelfinger, F. J. 1968. Digestive disease as a National problem. V. Gallstones. Gastroenterology. 55: 102.
29. Friedman, G. D., W. B. Kannel, and T. R. Dawber. 1966. The epidemiology of gallbladder disease: observations in the Framingham Study. J. Chron. Dis. 19: 273.

30. Thistle, J. L., K. L. Eckhart, R. E. Nensel, F. T. Nobrega, G. G. Poehling, M. Reimer, and L. J. Schoenfield. 1971. Prevalence of gallbladder disease among Chippewa Indians. Mayo Clin. Proc. 46: 603.

31. Grundy, S. M., and E. H. Ahrens, Jr. 1969. Measurement of cholesterol turnover, synthesis, and absorption in man, carried out by isotope kinetic and sterol balance methods. J. Lipid Res. 10: 91.

32. Grundy, S. M., E. H. Ahrens, Jr., and J. Davignon. 1969. The interaction of cholesterol absorption and cholesterol synthesis in man. J. Lipid Res. 10: 304.

33. Grundy, S. M., and E. H. Ahrens, Jr. 1970. The effects of unsaturated dietary fats on absorption, excretion, synthesis, and distribution of cholesterol in man. J. Clin. Invest. 49 : 1135.

34. Grundy, S. M., E. H. Ahrens, Jr., G. Salen, P. H. Schreibman, and P. J. Nestel. 1972. Mechanisms of action of clofibrate on cholesterol metabolism in patients with hyperlipidemia. J. Lipid Res. 13: 531.

35. Connor, W. E., D. T. Witiak, D. B. Stone, and M. L. Armstrong. 1969. Cholesterol balance and fecal neutral steroid and bile acid excretion in normal men fed dietary fats of different fatty acid composition. J. Clin. Invest. 48: 1363.

36. Miettinen, T. A. 1971. Cholesterol production in obesity. Circulation. $44: 842$.

37. Heaton, K. W., and A. E. Read. 1969. Association of gallstones with disorders of terminal ileum. Gut. 10: 414. (Abstr.)

38. Borstrom, B., G. Lundh, and A. Hofmann. 1963. The site of absorption of conjugated bile salts in man. Gastroenterology. 45 : 229.

39. Grundy, S. M., E. H. Ahrens, Jr., and G. Salen. 1971. Interruption of the enterohepatic circulation of bile acids in man: comparative effects of cholestyramine and ileal exclusion on cholesterol metabolism. J. Lab. Clin. Med. 78: 94.

40. Dam, H., P. M. Krogh Jensen, H. E. Kallehauge, and H. J. Fenger. 1971. Studies on human bile. V. Influence of cholestyramine treatment on the composition of bile in healthy subjects. Z. Ernaehrungswiss. 10: 188.

41. Wood, P. D., R. Shioda, D. L. Estrich, and S. D. Splitter. 1972. Effect of cholestyramine on composition of duodenal bile in obese human subjects. Metab. (Clin. Exp.). 21: 107.

42. Kenney, T. J., and J. T. Garbutt. 1970. Effect of cholestyramine on bile acid metabolism in normal man. Gastroenterology. 58: 966. (Abstr.)

43. Shefer, S., S. Hauser, I. Bekersky, and E. H. Mosbach. 1969. Feedback regulation of bile acid biosynthesis in the rat. J. Lipid Res. 10: 646.

44. Boyd, G. S., and I. W. Percy-Robb. 1971. Enzymatic regulation of bile acid synthesis. Am. J. Med. 51: 580.

45. Nestel, P. J., H. M. Whyte, DeW. S. Goodman. 1969. Distribution and turnover of cholesterol in humans. $J$. Clin. Invest. 48: 982.

46. Dietschy, J. M., and M. D. Siperstein. 1965. Cholesterol synthesis by the gastrointestinal tract: localization and mechanisms of control. J. Clin. Invest. 44: 1311.

47. Dietschy, J. M. 1968. The role of bile salts in controlling the rate of intestinal cholesterogenesis. J. Clin. Invest. $47: 286$. 
48. Fimognari, G. M., and V. M. Rodwell. 1965. Cholesterol biosynthesis; mevalonic synthesis inhibited by bile salts. Science (Wash. D. C.). 147 : 1038.

49. Back, P., B. Hamprecht, and F. Lynen. 1969. Regulation of cholesterol biosynthesis in rat liver: diurnal changes of activity and influence of bile acids. Arch. Biochem. Biophys. 133: 11.

50. E. A. Shaffer, J. W. Braasch, and D. M. Small. 1972. The influence of cholecystectomy on bile composition in cholesterol gallstone patients. Gastroenterology. 62: 809. (Abstr.)

51. Thistle, J. L., and L. J. Schoenfield. 1971. Lithogenic bile among young Indian women; lithogenic potential decreased with chenodeoxycholic acid. $N$. Engl. J. Med. $284: 177$.
52. Kirchman, E. H., D. Pertsemlidis, E. H. Ahrens, Jr., and A. E. Kark. 1970. Total body cholesterol content and distribution in dogs: effects of bile diversion and cholesterol feeding. Surg. Forum. 21 : 403.

53. Wilson, J. D. 1964. The quantification of cholesterol excretion and degradation in the isotopic steady state in the rat: the influence of dietary cholesterol. J. Lipid Res. 5: 409.

54. Redinger, R. N., and D. M. Small. 1971. The effect of phenobarbital on bile salt metabolism and cholesterol secretion in the primate. J. Clin. Invest. 50: 76a. (Abstr.)

55. Danzinger, R. G., A. F. Hofmann, L. J. Schoenfield, and J. L. Thistle. 1972. Dissolution of cholesterol gallstones by chenodeoxycholic acid. N. Engl. J. Med. 286: 1. 